\title{
What forms of \\ communication did a music therapy student use in her work with high school students who have special needs, and why?
}

Sarah Curtain

300356505

An exegesis submitted to Victoria University of Wellington in partial fulfillment of the requirements for the Master of Music Therapy at the New Zealand School of Music 


\section{Abstract}

This research project is aimed at answering the question: What forms of communication did a music therapy student use in her work with high school students who have special needs, and why? As communication is one of the primary goals for children with Autistic Spectrum Disorder (ASD) and other learning difficulties, (Gadberry 2011) I, as the music therapy student and researcher explored different forms of communication used in my practice and the reasoning behind them using Secondary Analysis of Data and Thematic Analysis. Forms of communication discussed include musical communication, social communication, direct instruction, gestures, key signs from New Zealand Sign Language, verbal communication, visual communication, technology and Augmentative and Alternative Communication systems, and combinations of each. The wide variety of reasons for my use of these forms of communication include, but are not limited to: supporting engagement, encouraging communication, promoting self-regulation, encouraging choice-making and turntaking, supporting socialization and interaction and reinforcing behavioural messages. The research was informed by my clinical work on placement at a learning support centre for children with special needs at a high school. The concepts of music as therapy and music in therapy are explored in relation to music therapy work involving different forms of communication. My conclusions support the use of various forms of communication in music therapy in special needs education settings when aligned with a focus on music, improvisation and the individual participant. 


\section{Acknowledgements}

First and foremost: to Dr Daphne Rickson. Thank you for your patience, understanding, wisdom and honesty.

To Dr Sarah Hoskyns - your compassion and encouragement have been invaluable.

To Pip- thank you for encouraging me to develop my practice by honouring my own musicianship, and for your words of comfort when they were most needed.

Thank you to my clinical liaisons, staff and participants at each of the facilities I have had the privilege to work at on placement. You have helped me to develop my music therapy practice, and I am endlessly grateful to and inspired by each of you.

My classmates. Thank you for the giggles, the tea, the popcorn and most importantly, the music.

My family. Mum and Dad, I will never be able to thank you enough for the wonderful opportunities I've been given. Thanks to my many siblings for both the encouragement and distraction as they were needed, and my friends for your endless love and support.

And finally, thank you to Jerome, for always looking in the same direction with me. 


\section{Table of Contents}

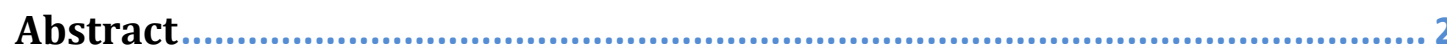

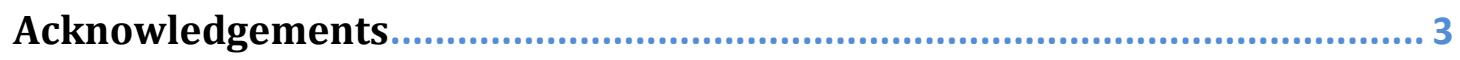

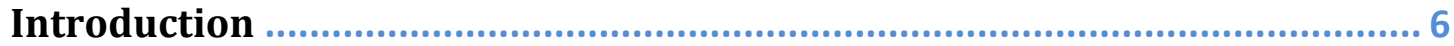

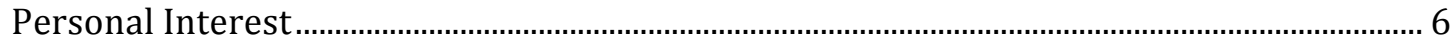

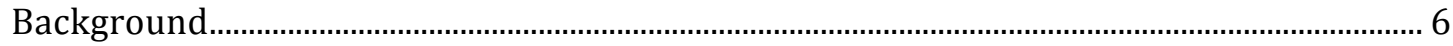

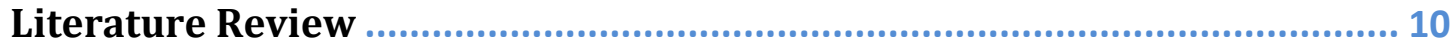

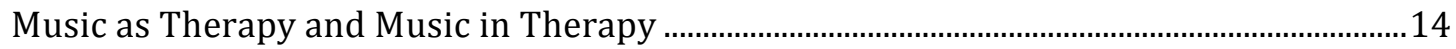

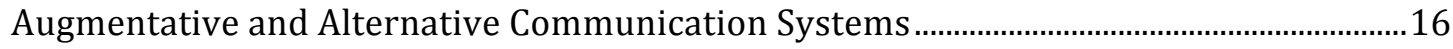

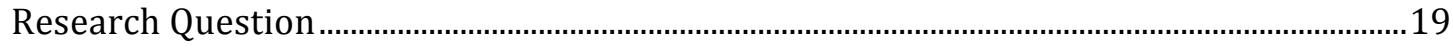

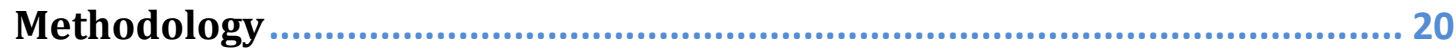

Secondary Analysis as a Methodology ……………………………………………………………....20

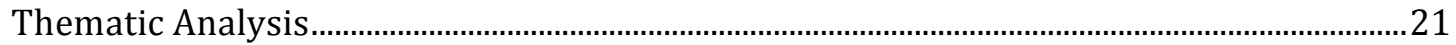

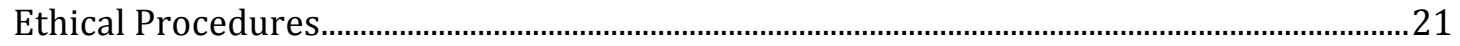

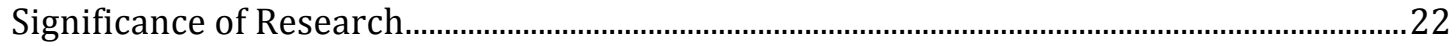

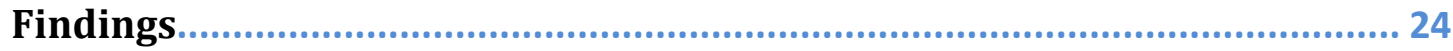

Research Analysis Process ...................................................................................................................24

Forms of Communication Used and Why ……………………………………………………...2

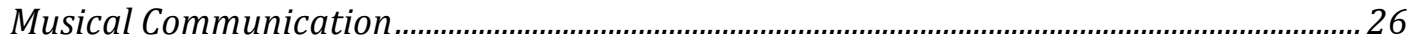

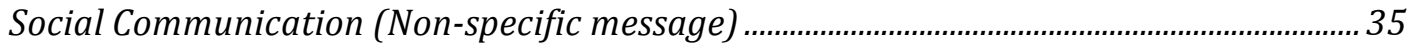

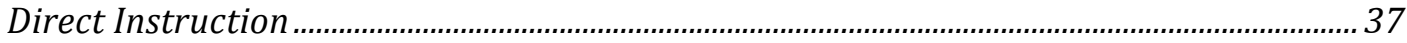

Gestures as a tool for communication..................................................................................................39

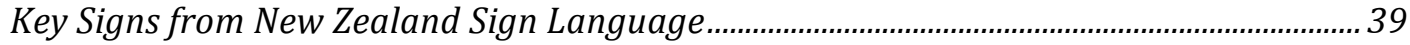

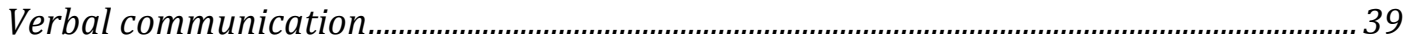

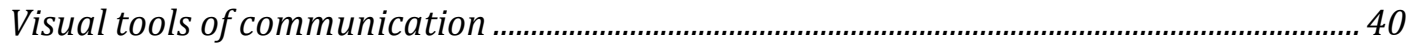

Technology/Augmentative and Alternative Communication Systems...................................... 42

Combinations of Forms of Communication........................................................................................ 43

Techniques Used ...............................................................................................................................................46

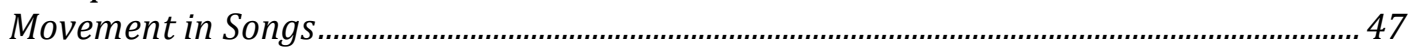

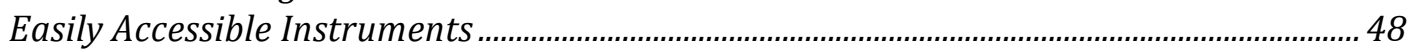

Varied Guitar Accompaniment ......................................................................................................... 48

Playful Dialogue .............................................................................................................................. 49

Emphasizing the Beat with Guitar Accompaniment....................................................................... 49

Emphasizing Suspense with Guitar Accompaniment .................................................................... 49

Finger-Picking Guitar Playing ............................................................................................................. 50

Manipulating the Musical Elements - Dynamics, Tempo and Silence .................................... 50

Modelling - Core Board, Drumming, Dynamics, Rhythm and Body Language and Group

Tempo and Dynamics ......................................................................................................................... 51

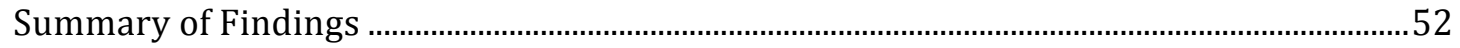

Discussion and Limitations ....................................................................... 54

Discussion of Techniques Used........................................................................................................54

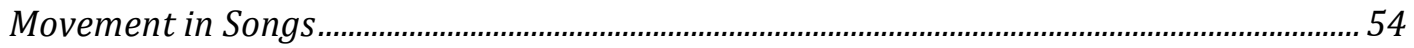

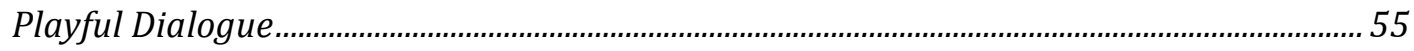

Manipulating the Musical Elements - Dynamics, Tempo and Silence........................................ 55

Discussion of Musical Communication .................................................................................................56

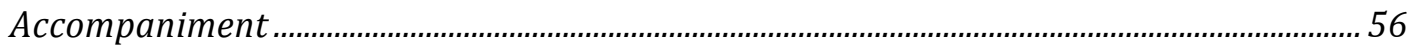

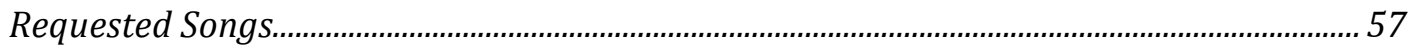

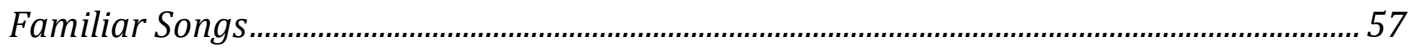

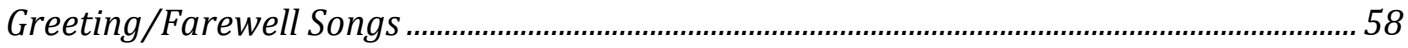




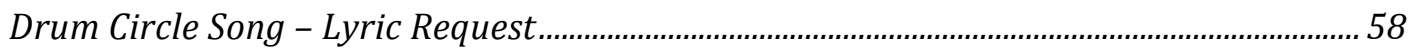

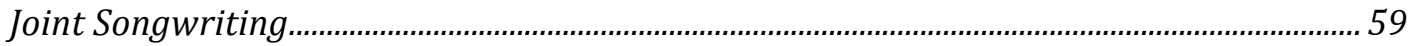

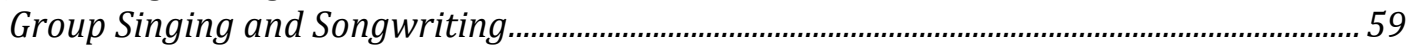

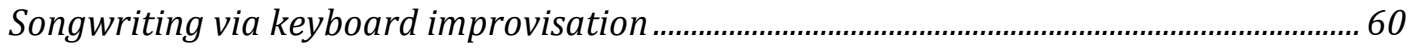

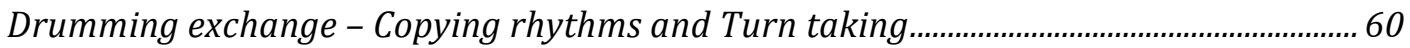

Discussion of Musical and Visual Communication .....................................................................61

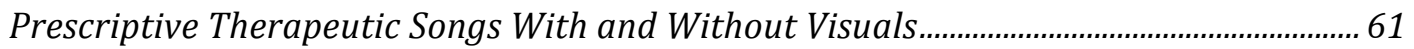

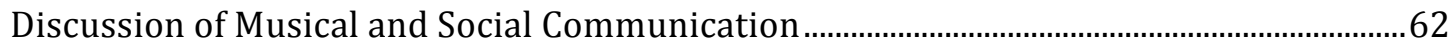

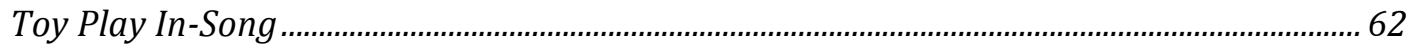

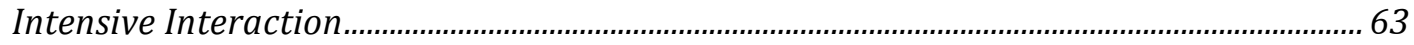

Discussion of Augmentative and Alternative Communication Systems ...............................64

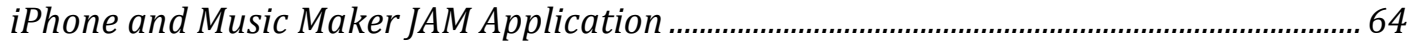

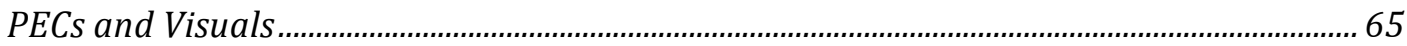

Discussion of Sign Language - Key Signs from NZSL ............................................................66

Discussion of Direct Instruction ...............................................................................................6

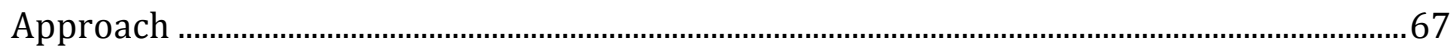

Music as Therapy and Music in Therapy ……………............................................................6

Conclusion .......................................................................... 70

References ............................................................................ 72

Appendices - Appendix A .............................................................. 83

Appendix B - Case Vignette Information and Consent Form …………………………….....8

Appendix C - Case Study Information and Consent Form .......................................................85 


\section{Introduction}

\section{Personal Interest}

As a lifelong musician, I have always had a keen interest in musical communication. It is now well known within the music therapy community that music evokes meaning and emotion that has the potential to transcend age and ability (Bunt \& Stige, 2014, p. 2). I've seen particular music and artists convey messages that couldn't quite be communicated via language alone. In my Bachelor degree studying jazz music, I experienced the conversation musicians can have strictly through musical improvisation. This back and forth could at times be emotional and mesmerizing. I have thus always wondered how powerful this tool of musical communication can be and what it might accomplish.

As I began my Masters study I developed my interest in the different forms of communication we use, especially in a therapeutic context. Gestures, visuals, technology and sign language and the possibility of their integration in music therapy began to spark my interest. I became especially interested in New Zealand Sign Language and took a few beginners' courses. It fascinated me how a silent language could be so inherently musical, and I wondered how it and other varying forms of communication could be used within music therapy.

\section{Background}

This research was informed by and conducted following a period of practice on placement as a student music therapist at a learning support centre at a high 
school. The centre provides individualized learning programmes for students who meet the criteria for the Ongoing Resourcing Schemes (ORS) (Ministry of Education, 2016). It includes four classes of adolescents (approximately ten students in each class, aged 13-21) with physical, learning and/or multiple difficulties and one class of adolescents who are d/Deaf ${ }^{1}$. Other diagnoses include Autism Spectrum Disorder (ASD), Prader-Willi syndrome and Down syndrome. There is a very broad range of student ability and need. While students are integrated into mainstream learning, the workforce and other activities in the general community when appropriate, the centre is the foundation of learning for all.

Gadberry (2011) asserts that communication is one of the primary goals for children with ASD as they lack a viable communication system, and that as many as $50 \%$ of children with ASD will not develop functional speech. Communication and socialization skills are generally impaired in autistic children (Joseph \& Tager - Flusberg, 2009; American Psychiatric Association, 2013), and they can often perceive their environment as confusing and frenzied. They thus have a propensity for structure and routine (Schuler, Prizant \& Wetherby, 1997). Students who are non-verbal due to other conditions and diagnoses also present with communicative difficulties in their learning. Music therapy offers unique opportunities for nonverbal communication. Improvisations in a music therapy

\footnotetext{
${ }^{1} \mathrm{~d} /$ Deaf is used here to acknowledge the difference between "Deaf" persons, who belong to a Deaf community, identify themselves as Deaf and/or prefer to use a particular sign language to communicate (e.g. New Zealand Sign Language) and "deaf" persons, who may have limited hearing and may or may not belong to a Deaf community (Ministry of Education, 2010).
} 
context for example offer "both a medium of enjoyment and expression for the client and at the same time a means to developing enhanced expressive and communicative music skills" (Aigen, 2005). In addition, as Aigen notes, it is also possible to hear interpersonal communication in music. However, while musical communication can be highly valuable for expressing the self, expressing and receiving emotions, and connecting with others, music therapy also provides a setting where other forms of communication can be rehearsed.

In a school setting, music therapists collaborate with team members to determine whether other means of communication will be used in music therapy sessions with learners. For example d/Deaf learners might be familiar with New Zealand Sign Language (NZSL) while those with learning disabilities might use it in a simplified manner (Ministry of Education, 2006). A music therapist might introduce these communication tools into her sessions alongside usual verbal, gestural, and facial expressions. Additional interventions to promote learning might include using a variety of visual, auditory, and kinaesthetic experiences during music therapy sessions (Adamek \& Darrow, 2005).

I thus believed an investigation into the forms of communication and the reasoning for their use in a music therapy context to be an appropriate research topic for this setting. I understood that forms of communication might include, but would not be limited to; musical communication including improvisation and the use of the musical elements, communication through music including lyrics and song writing, the use of 'aids' in a music therapy session including Augmentative and Alternative Communication Systems (Gadberry, 2011), 
written and verbal prompts, and the use of the 'therapist' including body language and sign language (Ministry of Education, 2006). My findings would be in broad in contrast to, for example, microanalysis of musical communication or facial expression. However, broad findings would inform readers about the balance of musical and 'non-musical' communication in music therapy sessions in school settings.

I was present for three days a week at the centre, facilitating group music therapy sessions with initially four of the five learning support classes (excluding the class of d/Deaf ORS students) approximately once a week. This reduced to two of the five classes, and one class aimed specifically at improving communication skills with students who had limited verbal speech or were completely non-verbal. I also facilitated weekly/bi-weekly individual sessions with approximately 17 students referred for music therapy by staff, which were eventually reduced to 14 . The centre has an open, easily accessible layout and features five large and generously resourced classrooms for learning, essential amenities and a centrally located playground area. A room, resourced with a variety of instruments and a keyboard, was available specifically for my office use and my individual music therapy sessions with students.

I provided information for students' IEPs, or Individualized Education Plans (Ministry of Education, 2011) and other reports, and attended regular staff meetings. My clinical liaison at the centre, research supervisor and visiting music therapist were available for consultation as required and provided regular supervision 


\section{Literature Review}

The following describes the literature relating to techniques, approaches and methods of communication used by music therapists in special needs populations. Although there is a sufficient quantity of literature commenting on music therapy work with special needs populations, there seems to be a lack of literature relating specifically to the use of different forms of communication in music therapy practice with this population. However, techniques used to enhance communication do emerge when examining the relevant literature.

In aid of communication, music therapists have used a number of techniques and methods in this setting. An analysis of music therapy programme goals with clients with ASD found that interactive instrument playing, musical instrument instruction, interactive singing and song choices were the most common interventions used by music therapists working in this field (Kaplan \& Steele, 2005). Tomlinson (2012) suggests that, when working in schools with children who have special needs, imitation can be a powerful tool to enhance communication. A few examples of student research (Clerkin, 2013; Hall, 2014, Savaiinaea, 2009; Wang, 2010) illuminated a number of music therapy techniques applicable to the experience of enhancing communication when working with children in schools with learning difficulties, including leading, using repetition, utilising contrasting musical elements, improvisation, empathetic playing and creating a contact song. Different forms of communication were described among these approaches and techniques. Clerkin (2013) emphasized the positive effect of movement, describing how physically moving closer to student's instruments incited more energy into their playing. 
Hall (2014) in particular found that different forms of communication, such as songs sung in the students' first language, modelling verbal language, using symbols and alternative communication devices, giving instructions through lyrics and using action songs with matching movements were supportive in her work. The beneficial use of familiar songs was described by Walworth (2003), who found decreased anxiety levels in hospital patients who listened to a preferred song or musical genre in anxiety-provoking medical procedures. The use of familiar songs was found by Dassa (2014) to encourage conversation in patients with Alzheimer's disease. It is important to note, however, that these last two studies relate only to music therapy practice and not to a special needs setting.

Aldridge, Gustorff and Neugebauer (1995a) emphasized the importance of hand movements and gestures in the role of non-verbal communication and emotional expression, whilst Bell, Perry, Peng and Miller (2014) state that music therapists use joining in and turn-taking activities for children with ASD to specifically encourage communication and social interaction. Turn taking and group singing was also found to benefit communication skills with severely and multiply disabled children in Perry's work (2003). Beathard and Krout (2008) used a variety of musical interventions and visual and interactive aids as well as an engaging and playful dialogue. Hello and Goodbye Songs, using instruments as rewards, gathering drum songs and improvisation were some of the musical interventions used, whereas visual and interactive aids included sign language, gestures, movement, instrument visuals, toys, books, drawings, The Picture Exchange Communication System (Bondy \& Frost, 1994), flash cards and props. 
The case study also asserts that brief pauses in the music, along with hand movements, were effective in motivating the participant to respond or vocalise (Beathard \& Krout, 2008). Songs utilised in morning greeting routines (composed individually for each child) communicate a welcome to students and establish routine, and were found by Kern, Wolery \& Aldridge (2007) to be beneficial in assisting participants to greet, enter a classroom and engage in play. The manipulation of tempo was most effectively used in Edgerton's work (as cited in Markworth, 2014). Meadows' (1997) proposed methods included instrumental activities, vocal activities, movement to maintain or increase fine and gross motor skills, and receptive methods. The latter describes therapy in which the child receives or listens to music. Composed songs and improvisational therapy were the predominant musical interventions used in Simpson \& Keen's (2011) review of the literature.

Particular music therapy approaches in this context were emphasised. Bayes et. al. (2013) state that, when working with students with intellectual disability, working with their natural motivation can boost needed communication skills, suggesting that a sensitivity to a child's individuality is necessary in this setting. McTier (2012) discusses the importance of the concept of play in music therapy with this same participant group as it supports creativity and thus self-discovery. Beathard \& Krout (2008) described a mixture of behavioural, improvisational and creative approaches in their clinical case study with childhood apraxia of speech. Aldridge, Gustorff \& Neugebauer (1995b) also suggest a creative music therapy approach for working with this population. Different therapist orientations were described by Meadows (1997). The orientations described 
included recreational orientation (in which the therapist is concerned with providing musical entertainment experiences, such as concerts), behavioural orientation (in which the therapist is concerned with influencing children regarding a specific behaviour), educational orientation (which emphasises developmental or curricular goals) and healing orientation (which uses therapy to support wellbeing and health). Improvisational music therapy is described as an approach that utilises improvisation as the primary therapeutic intervention (Geretsegger, Holck, Carpente, Elefant, Kim \& Gold, 2015). It has proven more successful in facilitating joint attention and non-verbal communication skills in autistic children than toy play, and can assist in developing flexibility within a structured framework (Kim, Wigram \& Gold, 2008; Kim, Wigram \& Gold (2009). The importance of improvisational and music-centred music therapy for autistic children was emphasized by Nordoff \& Robbins (1965), who asserted that autistic children can move between experiences only when the music is individualized and their own, and that the goal is a complete musical experience for both therapist and participant. It is worthwhile noting that Whipple, Gfeller, Driscoll, Oleson and McGregor (2015) proposed that music therapists should consider the fact that the expression of emotion or movement could be decoded differently by a student with a communication disorder, and that clinicians should keep this in mind when choosing music. Kalas (2012) supports this, suggesting that simple, predictable music encourages joint attention in children with ASD (unless higher levels of functioning demand complexity). 


\section{Music as Therapy and Music in Therapy}

The concepts of 'music in therapy' and 'music as therapy' are relevant to this research as the use of different forms of communication in music therapy could potentially confuse the intended focus of the therapeutic intervention. There is a difference of opinion in the literature regarding whether other interventions used alongside music (such as different communication tools and aids) detract from or add to the validity of music therapy.

Bruscia (1987) was the first to discuss the concepts of 'music as therapy' and 'music in therapy'. He describes music as the primary stimulus and response medium (or facilitator) of therapeutic change in 'music as therapy'- whereas in 'music in therapy', the therapeutic relationship is the agent of change, and music is used in aid of this. Bruscia (1998) elaborates on this in later years, introducing the concepts of music as psychotherapy (therapy using music as the main medium e.g. improvisation without verbal prompting) music-centred psychotherapy (therapy using music as the main medium with allowances, e.g. improvising with verbal prompting) music in psychotherapy (therapy using music and discussion, e.g. lyric replacement song writing) and verbal psychotherapy with music (discussion of music, e.g. discussing song lyrics).

The concept of 'music as therapy' is highly relevant to the notion of Paul Nordoff and Clive Robbins's 'Music Child', which they describe as the individualized musicality inborn in each child and which they refer to particularly when referencing work with handicapped children (1977). They state that, in creative 
music therapy emotional experiences, form, order, tempo, rhythm and melodic elements are available within them for the 'Music Child' to access and develop.

Aigen (2005; 2014a: 2014b) draws upon the concept of 'music as therapy' when describing music-centred music therapy, explaining that the musical experience in music therapy is self-justifying, and should thus be the primary goal. Essentially, he proposes that when practicing music as therapy, a therapist and participant strives to achieve musical expression, whereas non-musical goals are the primary focus of 'music in therapy'. Since the musical experience in therapy can prove to be more effective in facilitating mutually enjoyable interpersonal and communicative encounters than other interventions, such as toy play, (Thompson \& McFerran, 2015) perhaps the thought here is that a music-centred approach is not only more beneficial, but ideally used without other intervention. Strange (2012), however, comments that when working with special needs populations in schools he identifies with a music-centred approach, but maintains that the facilitator's interpretations and decisions are required to support this.

Straus (2014) stated that since a cure for autism is neither possible nor desirable, music therapists might attempt to enhance self-expression, knowledge and engagement in mutual music between the therapist and participant, thus aligning with a more 'music as therapy' view. Oldfield (2006) stated that though her method was musical, she used music as a means to achieve non-musical aims in her work with children who have special needs. She maintained that it was important to focus on a child's abilities rather than limitations, and utilized in her 
work movement and songs with Makaton signs (a simplified version of British sign language often used to assist children with language difficulties to communicate and develop speech) (Grove \& Walker, 2009). It could be hypothesized that her view aligns more with a 'music in therapy' view, and yet her music-centeredness in her approach suggests she was using both approaches in parallel.

\section{Augmentative and Alternative Communication Systems}

Gadberry (2011) suggests that the use of alternate means of communication, such as Augmentative and Alternative Communication systems (AAC) is necessary when working with and educating children whose communication needs are not otherwise met. AAC includes the use of pictures, electronic devices, gestures, pointing and signing. Gadberry's study (2011), discovered that there is a low number of music therapists utilising AAC with students who possess the systems and found this, and the lack of training for music therapists in the use of AAC systems, to be concerning. Gadberry (2011) stated that AAC systems could model communication, promote choice making and thus provide benefits in communication. In a later study, the same author suggested that using AAC results in a higher frequency of a participant's intentional communicative acts and functions when compared to music therapy practice without the use of AAC (Gadberry, 2012).

The Picture Exchange Communication System, or PECs, teaches a participant to give a picture of a desired image to a partner in exchange for a specific item 
(Bondy \& Frost, 1994). A study discovered that this system and Voice Output Communication Aids (VOCAs) are similarly effective in enabling students to make requests, and found improvement in communicative skills across the majority of participants in the study after the use of these interventions (Lancioni et. al, 2007).

An examination of the state of research and practice in AAC systems with special needs populations found some limitations in the use of these systems. One piece of literature suggests that if a non-verbal mode of communication were utilised, a child would have no motivation to develop speech. The thought here is that abstract approaches to the symbols used in AAC systems are also likely to be misaligned with the typical child's learning experiences (Wilkinson \& Hennig, 2007). This, however, is a highly contestable stance. Malloy (2003) stressed the advantages of sign language systems in relation to boosting language, development, literacy and even the quality of speech in d/Deaf children. In fact, seven studies that compared the use of sign language and spoken English by teachers of kindergarten and pre-school students in public schools to teachers who used only spoken English revealed that the students in the sign language class scored higher in standardized tests related to vocabulary development (Waldman, 2001). Allen, Letteri, Choi, and Dang (2014) assert that the early use of sign language in $\mathrm{d} /$ Deaf children has positive effects on letter knowledge, social adaptability, cognitive behavioural milestones and sustained visual attention - each crucial for academic success. Furthermore, it can contribute greatly to literacy and reading comprehension later in life. Neuroimaging studies suggest that exposure to a visual language develops phonological skill similarly 
to exposure to an auditory language (Petitto \& Marentette, 1991). Allen et al. (2014) also support the Qualitative Similarity Hypothesis, the premise of which is that $d$ /Deaf or hard of hearing children and adolescents will eventually meet the developmental stage that matches the chronological age of hearing students (Paul \& Lee, 2010). The support of this hypothesis, however, is conditional, on the basis that it does not pertain to one specific modality (aural or visual) (Allen et al., 2014). From an educator's perspective, using educational supports such as written words, colour coding, icons, echoing, the buddy system and other visual aids proved to be beneficial in teaching those with special needs (Whipple \& VanWeelden, 2012). Technology's evolving role in modern culture has seen an increase in easily accessible, hand-held media devices and applications (apps). This presents opportunities for students with ASD to develop their communicative skills using laptops, tablets and/or special purpose software (Shane, Laubscher, Schlosser, Flynn, Sorce \& Ambramson, 2012). For example, Xin and Leonard (2014) found that students who were given access to iPads with a speech-generating application increased their initiation of requests, responses to questions and social comments made inside and outside of the classroom. An example of an application used to facilitate musical experiences is BeatBox Looper (Guilluy, 2016) whereas Tap to Talk was an effective AAC app to establish a participant's choices and needs (Knight, 2013). According to Clements-Cortes (2013), high-tech music technologies used in music therapy include computer-assisted devices, specialized input and switch-activated devices, recording technology, music software applications and music video games. These can be used with participants of any age to address goals such as: physical rehabilitation, emotional expression, social/cognitive development, 
enhanced communication, relaxation, healing/reducing pain and building selfesteem and confidence (Clements-Cortes, 2013).

The number of music therapists using technology in their practice is increasing, especially since technology has become so affordable, accessible and portable. Applications for musical instruments, notation/composition, listening, improvisation and recording playback may benefit music therapists, who should consider integrating them into their practice. They could also assist in composing or performing songs with stronger instrumental authenticity. It should be noted, however, that relying on technology completely could negatively impact the role of the therapist and that the therapist's experience and expertise with the technology should be considered before integrating it into their practice (Knight, 2013). According to Hahna, Hadley, Miller and Bonaventura's survey (2012), $71 \%$ of music therapy respondents reported that they currently or have previously used musical technology, including: recording and amplification techniques, electronic MIDI (musical instrument digital interface) instruments, specialist input software devices, vibroacoustic therapy equipment, augmentative and alternative communication systems and mp3 players. The survey respondents also report that these interventions were used alongside acoustic instrument playing and only if the needs of a participant were not met by said acoustic instruments (Hahna et al., 2012).

\section{Research Question}

What forms of communication did a music therapy student use in her work with high school students who have special needs, and why? 


\section{Methodology}

In order to answer the research question of what forms of communication I might use in my work with high school students who have special needs and why, I utilized Secondary Analysis of Data as my chosen methodology. This methodology involved re-analysing data in order to answer new questions with old data (Glass, 1976). I used my clinical data, collected from my work as a music therapy student on placement, and examined it in order to highlight which forms of communication were utilized and for what purpose in this setting. The themes and recurrent concepts that have emerged from this secondary analysis have allowed me to answer my research question, and thus inform others of its findings.

\section{Secondary Analysis as a Methodology}

This research project involved the use of Secondary Analysis of Data. Existing qualitative data, retrieved from my clinical work as a student music therapist, was analysed to answer the research question. I used Thematic Analysis as my method of identifying, analysing and reporting themes or patterns within this data (Braun \& Clarke, 2006).

I generated clinical data from my work with adolescents with special needs at a learning support centre at a high school. Data sources include clinical notes and a reflective journal, and the data was drawn from ten days of work between the $27^{\text {th }}$ of July and the $31^{\text {st }}$ of August 2016 . Saturation is the point at which no new findings are emerging. Due to the broad nature of the research question and the 
large variety of communication forms used in one day, saturation point was reached after analysing just 10 days of clinical notes.

\section{Thematic Analysis}

When my clinical work concluded, I became re-acquainted with the data, reading and re-reading it and taking note of information that related specifically to a form/forms of communication and/or the reasoning behind the use of these methods. I then generated initial codes by labelling interesting features across the data set. From there, I collated these codes into potential themes, or patterns, and reviewed said themes. Finally, I named these themes and detailed their specifics, outlining them and eventually producing the narrative of the analysis (Braun \& Clarke, 2006). Through the process of generating initial codes, developing categories from these codes and developing themes through a reorganisation of the initial analysis stages., I discovered what forms of communication I used, as a student music therapist on placement, with special needs students at a high school and the reasoning behind them (see Appendix 1 for data analysis example).

\section{Ethical Procedures}

I am currently a student music therapist completing my Masters of Music Therapy at the New Zealand School of Music, Victoria University of Wellington. As such, I abided by the Victoria University of Wellington Human Ethics Policy, (Victoria University of Wellington, n.d.) the New Zealand school of Music Ethical Guidelines for NZSM526 Research Projects (New Zealand School of Music, 2015), 
and the Code of Ethics for the Practice of Music Therapy in New Zealand (Music Therapy New Zealand, 2012). The VUW Human Ethics Committee has given generic approval to NZSM Master of Music therapy Programme ethical template for student research in NZSM 526 undertaken as observational studies, theoretical or case study research or action research (ref: 22131, 2015). This study has been judged to be low risk and, consequently, was not separately reviewed by any Human Ethics Committees.

The research focuses on my own clinical practice and indirect responses from those I worked with. As I initially intended to include a case vignette in this exegesis (the exclusion of which is explained in my discussion), I obtained informed consent in writing from the parents/guardians of the participants and/or the participants themselves (see Appendices B and C). I use pseudonyms when discussing the facility and indirect participants in order to maintain anonymity. Readers may still be able to identify the facility, and those concerned have been informed of this risk. Summaries of the research will be made available to the facility where clinical work was undertaken and, as appropriate, to the families of those students involved in the clinical work. Clinical data will be destroyed five years after the research process has been completed.

\section{Significance of Research}

This research aims to provide an insight into the forms of communication used by a student music therapist within a learning support centre at a high school and the reasoning behind the use of each communicative method. The rehearsal 
of interpersonal communication is particularly important when working with this participant group as they lack a viable communication system (Gadberry (2011). Investigating the specifics of how music therapy could interact with different forms of communication could thus benefit the special needs education sector, future music therapists and the wider community. 


\section{Findings}

\section{Research Analysis Process}

I found the Secondary and Thematic Analysis processes challenging at times when it came to the labelling and re-labelling of categories and themes. Analysing such a broad range of forms of communication and techniques used in my work was difficult, as one intervention would often seem to fall into multiple categories. This is why I eventually decided to include some combinations of different forms of communication. This seems to suggest that my music therapy practice in this special needs setting often involved an integration of various forms of communication, rather than just one at a time.

\section{Forms of Communication Used and Why}

The graphic on the following page illustrates the major categories that emerged from the data and the themes that were then drawn from them. 


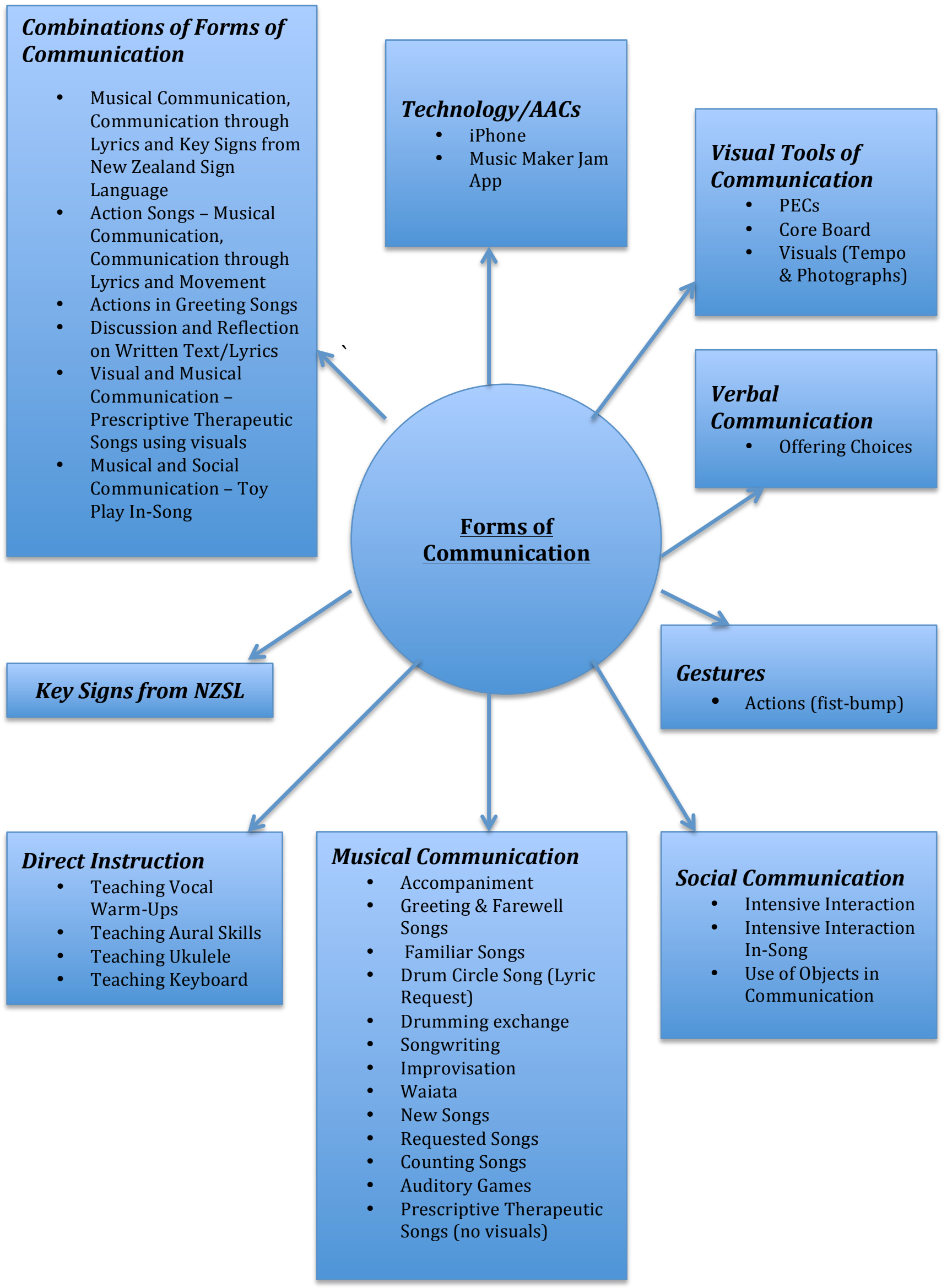




\section{Musical Communication}

\section{Accompaniment (keyboard and vocal)}

I accompanied students' contributions with my voice, and with the keyboard.

This supported their engagement, communication and encouraged them to initiate new vocalizations/actions. While sharing music they were also developing aural skills, memory, and fine motor skills. For example:

The improvisation I had with Rachel was... a bit of a 'wow' moment, really. My supervisor's comments that she wished she'd recorded it for me and that it was a strong example of musical communication really made me feel confident in my skills and, of course, proud of Rachel! We'd improvised on the keyboard, following each other around and calling to each other using short phrases, until she played something that reminded me of Kumbaya and I played an accompaniment and sang to it. I'm unsure as to whether Rachel already knew the melody or whether it was by ear, but she began to play it with me! It was such an amazing moment. We didn't need to talk, we didn't need to sign, and we didn't need to use any visuals. It was just the music and us and we made a connection there that I'm not sure I can even articulate. This is what it comes down to, for me. I'm a big advocate of using whatever communicative tools I can (that work!) with music therapy, but at the end of the day, music communicates so much on its own, and as a student music therapist especially it should always be my priority.

\section{Greeting Song}

I used a pre-composed hello song in almost every session to signal the beginning of our time together and greet the students with music. The lyrics reinforced the greeting. Repeating this song at the beginning of every session provided a sense of structure that often provides comfort for students with ASD. The precomposed song leaves space at the end of phrases for the students to respond to me musically or with movement, such as in this example:

Beth is following musical cues much easier. She now understands when I leave space for her to sing 'Hello' and 'Goodbye' and sings these clearly back to me. It also encourages interaction and eye contact with peers through the use of musical communication. 


\section{Farewell Song}

A pre-composed goodbye song was used in almost every session to communicate a farewell and signal the end of a session. This musical reminder of finality reinforced the farewell emphasised in the lyrics and provided a sense of structure that was appreciated by some of the autistic students. This structure seemed to calm any anxieties about the order of their day and helped them to self-regulate. It was also used in order to ease students out of the session so that the transition between music therapy and the classroom wouldn't be too abrupt.

\section{Familiar Songs}

I used songs that were familiar/well known to the students in order to engage them more with the music or with specific instruments. This peaked their interest, energized them and offered insight into likes/dislikes and individual expression. This is possibly due to the fact that repeated, familiar songs that exist within structure and routine promote confidence in the students, allowing them to express themselves fully. These songs also served to calm students and provide an avenue of expression to help them regulate their emotions, to motivate students into movement and/or encourage students to make a choice. The latter is outlined in the following example:

Wes became very excited during Roar. He participated and made choices easily throughout the entire session, which is an achievement given his behaviour in recent weeks. During Roar he stood up, bobbed up and down in a dancing fashion, drummed, and 'Roared'....

Familiar songs were used to encourage controlled arm movements using instruments from students with limited mobility:

I then gave Lucy the orange shaker. She didn't grab it so I placed in the crook of her arm and played her next song choice. During 'Roar' she picked 
it up with her left hand and shook it as I sang, singing and laughing occasionally and tapping her right leg with her right hand.

Students were also motivated to lead their class or group at times when using a familiar song:

Drumming to the beat during 'Hey Jude' was a very containing exercise for the group. The teacher aides and Charlotte, who were more confident at keeping the beat than others, led the groups steadily and influenced the others positively.

Another reason for using familiar songs was to encourage vocalisation and/or verbalisation from students:

Ben has begun to sing more frequently during sessions. He made an effort to try to sing the 'toot toot chugga chugga' in one of his favourite songs, 'Big Red Car' (he achieved the vowel sounds, but struggles with consonants). He also engages vocally when we whistle in Don't Worry Be Happy, making the 'oo' shape with his mouth and singing through it in an effort to whistle. This makes him smile and laugh.

Familiar songs were also used in a conscious effort to build the therapeutic relationship over time:

Charlotte began to sing one of her favourite songs before we finished the session, and I played and sang it with her. This seems to have become 'our song', and Charlotte was smiling throughout it.

\section{Drum Circle Song - Lyrics Request}

I used a specific song in which the lyrics requested that the students take turns playing on a large drum, which was placed in the centre of a group circle. The song was used to encourage turn taking, self-regulation and the initiation of arm movement. Upon reflection, these lyrics 'Would you like to play on the drum?' imply that the students chose whether or not to participate. The song featured a driving beat that was easy to drum along to. After the previous lyric was repeated, the next one advised each student in turn that it was his or her turn to 
play. I would then repeat the chord progression to give the student the opportunity to 'solo' on the drums.

\section{Drumming exchange - Copying rhythms and turn taking}

I utilized drumming exchanges in which the participant/s and I would take turns copying and playing rhythms on the bongo drums. This would encourage hand/arm movement and the self-regulation required for said movements and turn-taking, as per this example:

Steven has improved greatly in his ability to control his movements in order to play in time. He speeds up often, but when I emphasized the beat in my own drumming and made my arm movements exaggerated, Steven slowed the speed of his arms and hands and watched me, timing his palm landing on the drum with mine visually.

This was accompanied by a drumming track created using the Music Maker JAM application on my iPhone (JAM just add music GmbH, 2017). I discuss the use of this app later in my findings.

\section{Songwriting (iPhone, Music Maker JAM App)}

I facilitated songwriting with the participants via the Music Maker JAM application on my iPhone (this application is discussed further later in my findings) (JAM just add music GmbH, 2017). Participants would record themselves playing an instrument, usually a drum, using the application to create a song. The songwriting here was in aid of encouraging expression, relaxation and a sense of mastery and confidence.

\section{Joint Songwriting}

Songwriting was used with two students who attended music therapy sessions together. The two students brainstormed themes and ideas and discussed how 
they could be expressed using music and lyrics. One student provided precomposed lyrics that were then edited as both students contributed different ideas. The songwriting here was used specifically to instil confidence and a sense of mastery, facilitate musical and emotional expression and provide an opportunity for turn taking and teamwork:

There were some conflicts with songwriting today, but a lovely moment emerged. Charlotte had difficulty compromising on some of her ideas and/or understanding why her sentence structure didn't make as much sense to Diego and I. When Diego suggested ideas, Charlotte initially rejected them, but through suggestions from me and mediation she came up with a new line that included a suggestion from Diego, another suggestion she remembered him making in a previous week and one of her own words. It was a lovely compromise.

\section{Group Songwriting}

I facilitated group songwriting with certain classes at the centre. The groups would brainstorm themes and ideas for lyrics, and at least one contribution was usually gathered from each participant regarding their likes and dislikes:

Using the specific method of going around to each class member and asking them what they like/dislike about school was a much more beneficial way to engage the class in the songwriting process. It also allowed each individual to contribute to the song.

I arranged their lyrics and musical ideas into songs that the classes eventually performed for their classroom teachers at the end of the year. Goals throughout this group songwriting process were to encourage group cooperation and turntaking, encourage both musical expression and expression through the use of lyrics and increase self-esteem by improving a set of skills.

\section{Songwriting via keyboard improvisation}

I facilitated songwriting with a particular student through an improvisation process on the keyboard. The composition eventually evolved into a song that 
could possibly be helpful in teaching how to count. Songwriting and improvisation were initially used here to encourage expression. The following example illustrates this process:

When we went to improvise on the keyboard, I asked Ashleigh what she'd like to play. She began to improvise and played in a jaunty manner, singing some of her frequently used adjectives like 'super' and 'great' and numbers up to 10 in an ascending fashion. The singing wasn't exactly melodic, but it was certainly rhythmic. I began to play a jaunty $C-G$ progression (as this was approximately the tonality Ashleigh was playing in) and sing about 'Super Number 10'. The lyrics were: 'Super number 10, super number 10, we're counting up then we count back down again. 1, 2, 3, 4, 5, 6, 7, 89 and 10, 109 8, 76 5, 4321 again!' Here, I used lyrics that Ashleigh sang like 'super' and numbers, and turned the improvisation into a counting song. Ashleigh enjoyed the song, giggling when we counted up and down. When I first sang 'Super Number 10', she looked at me with wide eyes. Singing the numbers forwards was simple for her - backwards was slightly more challenging (she made occasional mistakes).

\section{Improvisation (Hanging Chimes)}

I used improvisation using the hanging chimes specifically with students that were both less verbal and less mobile. The soothing sound of the chimes seemed to relax some participants. The simple motion of sweeping a hand through the chimes also made them easily accessible and engaging as per this example:

Before playing 'Let it Go' I moved the chimes around. When she heard the sound of them, Lucy vocalised, looked up and smiled, so I gave them to her to hold and play during the next song. She occasionally moved her hand up to play the chimes, and rested her head against their top bar...Every now and again I would sweep my hand through the chimes, which made Lucy giggle.

Improvising using this instrument was to encourage musical expression and communication, as well as to support the initiation of arm movement.

\section{Vocal Improvisation with Music Maker JAM App}

I used the Music Maker JAM application on my iPhone (JAM just add music $\mathrm{GmbH}, 2017)$ to facilitate improvisation with the students in order to encourage engagement and expression and build the therapeutic relationship. We would 
improvise vocally and with instruments over a track created using the application, which may have featured drum, bass or guitar loops.

\section{Improvisation (keyboard)}

I improvised with the students using the keyboard in order to facilitate expression and engage them with what was sometimes a favourite instrument, as seen in this example:

...In our improvisation, Ashleigh grinned when I played a glissando and copied me, starting from the top of the keyboard and going down to middle $C$ with her right hand. Our improvisation featured a lot of descending chromatic lines, which Ashleigh also liked to copy back to me, and more glissandos.

Improvising on the keyboard was also used to build the students' self-esteem by developing their skills and a sense of mastery.

\section{Improvisation (mbira)}

I improvised using the mbira with a less mobile student, as it was easily held and thus simple to access, as per this example:

I played the mbira, improvising, Lucy looked up immediately to find the source of the sound. She reached for the instrument, held it close to her face and played a few notes. She then smiled, laughed and sang with closed eyes, seemingly enjoying the music.

Improvisation on this instrument was used to encourage engagement, expression and arm movement.

\section{Song (Waiata)}

A group of students were learning basic Te Reo and singing some simple waiata

in the classroom. Though none of the students in that particular group were Maori themselves, singing a waiata to finish supported their learning in an area that is of cultural relevance to their community. It also provided an avenue of 
expression that might provide future connections if students were involved in a Maori community event.

\section{New Songs}

I introduced songs that were new to the students in the hope that they might be engaging for their age group and abilities, or because they presented an interesting musical challenge (as appropriate for individual students). Examples include songs that featured in popular films, used key words that were appropriate to accompany with NZSL or involved animals and animal noises: The group seemed to enjoy 'I Had a Rooster'. Each group member was able to contribute to the song in a way that was easy for him or her (e.g. animal sounds) but the music was new and exciting. This novelty factor plays an important role in this setting. It could reduce boredom and inattention and potentially improve memory function, as the students may be more likely to recall an exciting, fun event.

\section{Requested Songs}

I used songs that students had mentioned or brought as requests into our sessions. These songs reflected a direct interest from the student/s, which could lead to a possible avenue of musical expression, expression through the use of lyrics and overall engagement. I invited students who were a little more withdrawn and/or refused to participate in sessions to request favourite songs in order to help them engage more with the music and with their peers. With songs that were in any way associated with certain instruments I would try to incorporate the use of that instrument in our music, such as in this example with Charlotte: 
Charlotte introduced the kazoo herself this week - it was an instrument she had brought from home that was associated with her requested song. This suggested a possible interest in continuing on with this song, rather than trying it once and leaving it as we had done others.

\section{Song (Counting)}

I used a familiar song with a focus on counting, with a student who can have difficulty with self-regulation and maintaining focus throughout sessions. As we sang this counting song we both played freely on the keyboard, then I used the technique of leaving space at the end of the counting phrases in order to prompt her to respond with the next number. Using a favourite instrument along with this counting song seemed to engage her and heighten her focus.

\section{Auditory Games}

I used a musical activity with a focus on cooperation to improve aural and visual skills, turn taking and teamwork. A student would hide in a separate room while the rest of the group hid a certain small instrument. When the student was invited back in, the group and I directed them to the hidden instrument using our music with handheld instruments (louder/faster for closer, softer/slower for further away).

\section{Prescriptive Therapeutic Songs Without Visuals}

Prescriptive therapeutic songs without visuals were used with a participant because she can have difficulty with self-regulation, but also enjoys music therapy and is always eager to attend. The term prescriptive therapeutic songs here refers to an intervention similar to Pasiali's (2004) method of 'piggybacking' familiar melodies to accompany the lyrics of an individually composed social story and using a visual schedule of sessions to provide 
structure and reduce target behaviours with autistic children. The melodies used in my work, however, were often original compositions rather than existing tunes and featured simple melodies and chord I, IV and V progressions. The directives in these songs were also similar to Social Stories ${ }^{\mathrm{TM}}$, which involve integrating an individual's inclination for success in visual learning with behaviour modifications that are necessary for their education and development (Brownell, 2002; Raising Children Network, 2017). In Social Stories ${ }^{\mathrm{TM}}$, descriptive, directive, perspective and control sentence types are arranged and accompanied by visuals. This evolves into a step-by-step story that outlines certain expected behaviour or behaviours. (Brownell, 2002; Pasiali, 2004). The prescribed therapeutic songs I used did not involve visuals and did not necessarily include those sentence types, though Social Stories ${ }^{\mathrm{TM}}$ inspired them in terms of how they might help modify behaviour. The use of prescribed therapeutic songs allowed reinforcement via music and lyrics of expected behavioural messages, such as 'Taxi Time', which reinforced the expectation that she would walk outside to the taxi at the end of the day (which she had previously been refusing to do). Using these songs gave the student the opportunity to self-regulate and promote her memory and focus, as per this example:

With some repetition Beth was able to sing the new social story songs back to me. She laughed as we marched during 'Taxi Time' and this song worked to get her to leave her classroom at the end of the day.

\section{Social Communication (Non-specific message)}

\section{Intensive Interaction}


Intensive Interaction is the response of an individual's body language and facial expressions using playful imitation (Ephraim, 1986 cited in Culham, 2004 and Caldwell, 2006). Based around the interaction and relationship of mother and infant (Stern, 1977, 1985), this imitation and intimate interaction provides the child with the foundation to develop interactive, communicative and social skills (Papousek, 1995 cited in Graham, 2004). During Intensive Interaction, enjoyable interaction sequences between learners and interaction partners are developed in a relaxed manner. The learner leads and reacts whilst the facilitator responds to and joins in with the behaviour of the learner, developing the 'flow' of the interactive activity (Intensive Interaction Institute, 2017). In Intensive Interaction, the facilitator 'tunes in' to the client using imitation of body language, facial expressions and vocal sounds, whilst in music therapy a therapist 'tunes into' and adjusts to the client via matching or mirroring in order to facilitate a musical response (How, 2014; Caldwell, 2006). As modelled by a visiting speech language therapist, staff members practised Intensive Interaction throughout this session frequently, responding to and joining in with students' natural movements and body language back to them. This was in an effort to support communication, socialisation and interaction in the classroom.

\section{Song (Intensive Interaction)}

I used two specific pre-composed songs that modelled Intensive Interaction using movement to support socialisation and interaction in the classroom. Students would contribute a movement and their peers and I would copy it back to them. One of these songs involved asking the students to play two beats using body percussion, such as a clap of the hands and a stamp of the feet. This 
example highlights how intensive interaction and the turn-taking process engaged one particular student:

Daniel grew very excited before the Rhythm Song, laughing and clapping his hands quickly as it led up to his turn. He was able to show us a short pattern of 2 beats to follow.

\section{Use of objects in communication}

The use of instruments in play or as toys, e.g. rolling, dropping etc. was engaging for non-verbal students and encouraged vocalisation, eye contact and hand movement, as reflected in this example.

It seemed as if she wanted to drum something, so I handed her the small tambourine. She would wait a few seconds while I placed it on her lap, then move her hand to shake it off and giggle, making eye contact. I improvised a little song about the tambourine falling and we played this game for a few minutes.

Though the focus here was on the element of play more so than on musical improvisation, the combination of both after may have provided additional therapeutic benefits.

\section{Direct Instruction}

\section{Teaching Vocal Warm-ups}

I taught simple tongue twisters and vocal warm-ups to a particular highfunctioning student with autism in order to improve her enunciation, clarity of speech and communication skills. This particular student's struggles with mumbling and speech clarity often angered and upset her, and she could become aggressive when she was not understood. Teaching vocal warm-ups was thus also in an effort to build her confidence and self-esteem.

\section{Teaching Aural Skills}


When one student expressed confusion and interest in identifying different levels of pitch, I began teaching her simplified aural skills. We covered pitch exercises or games involving her listening to two notes and commenting on which note sounded higher or lower (as I played them one at a time on the keyboard). Building on this particular area of the student's interest was in an effort to build her musicianship and thus her self-esteem and sense of mastery. The student has also been involved in speech therapy as her low, monotone-like speech can sometimes be difficult to understand. I also thought that developing her aural skills might help enhance her awareness of the different vocal tones used in speech.

\section{Teaching Ukulele}

Simple ukulele skills were taught to particular students who had expressed interest in the instrument. Teaching was used in order to boost self-esteem by developing skills and a sense of mastery. Forming simple chord shapes and strumming/holding the ukulele also encouraged arm movement and developed fine motor skills:

Ashleigh was able to audibly play the chord $C$ on ukulele today (without other fingers barring the strings). It was momentary and she only held the position for a short while, but it seems that her fine motor skills might be improving in this regard.

\section{Teaching Keyboard}

I taught short, simple right-hand melodies and piano duets on the keyboard to particular students who had an interest in this instrument. Teaching piano skills was in an effort to elevate the students' self-esteem by building their confidence and sense of mastery in the skill. Only a few phrases were introduced at one time so as not to overwhelm the students: 
Jessica is doing well at learning short piano melodies in order to improve her confidence, so we've begun to learn a simplified version of a Passacaglia duet. My hope is that this builds Jessica's confidence as she improves her musicianship.

\section{Gestures as a tool for communication}

\section{Action (Fist-bump)}

I would employ gestures and actions that were familiar to the students, and part of their everyday culture. For example, I would give them a fist-bump, which commonly represents camaraderie and/or congratulations to adolescents. One student in particular engaged well with this action as a reward at the end of sessions and usually reached for it. I therefore used this action to engage the participant, support his initiation of arm movement and build our therapeutic relationship.

\section{Key Signs from New Zealand Sign Language}

After discussions with the teacher of the d/Deaf class at the centre and completing a course of New Zealand Sign Language, I began to use key signs with particular students in order to engage, communicate with them and give them the opportunity to use language in sessions if verbalisation was difficult for them. I used sign language frequently with one non-verbal student when asking him if he wanted/liked certain instruments or songs and communicating when the session would finish. Using key signs from NZSL would also occasionally support classroom learning and hand/arm movement.

\section{Verbal communication}

\section{offering Choices}


I used verbal communication with students in order to communicate and offer a choice between visuals or instruments. I often accompanied these verbal offers with body language, such as pointing.

\section{Visual tools of communication}

\section{PECs}

I used PECs (Bondy \& Frost, 1994) with the students primarily to promote turn taking, facilitate choices of songs or instruments, encourage turn taking and promote self-regulation and controlled arm movements. A variety of different images representing familiar songs, stuck onto cardboard and laminated, were available for the students' use. Depending on the individual and their current progress with making choices, two, three, or a variety of visuals were placed in their line of vision. They were then verbally asked to make a choice and take one visual from my hands or a flat surface. These were then stuck onto a numbered board using Velcro dots. After that chosen song was exchanged or chosen instrument used, it would then be my turn and we would continue, offering as many choices were appropriate for that student. Using a visual reminder seemed to calm students who may otherwise have had difficulty with turn taking, as per this example:

We used visuals to take turns choosing songs. When I told her teachers what we did afterwards, they said this was a 'wow' moment, and that they were very happy with this. They said she can be prone to tantrums and does not like to stay still, so it was remarkable that she did so.

This process proved useful in providing a visual reminder and structure for students with autism that benefited from knowing precisely how many activities they were expected to participate in during one session. Some students needed prompting (verbal or musical) than others in order to make a choice, and there 
were instances with less mobile students where their choices were mostly based upon their eye line and/or vocalisations.

Lucy seemed to find it difficult to choose songs today - we mostly went by her eye line as she would reach for myself or a teacher aide rather than a visual. Tried to move them closer to her eye line, to no effect until presented with a favourite, Five Little Monkeys. Chose this clearly.

\section{Core Board}

I used a device known as a Core Board that is used by students and team members to enhance students' use of PECs (Bondy \& Frost, 1994) and improve their conversation skills. This enables them to indicate 'I want', 'I like' and many different feelings regarding their choices or requests in order to enhance communication skills. These core boards and other visuals could help the students to make choices about elements of the music, such as faster/slower, lower/higher, etc. The boards also gave team members opportunities to ask the students whether they liked the songs after they were sung, and prompted them to answer. In one example:

The increased conversation seemed to motivate Wes to engage with Jeff, calling him by name a few times, and the two made eye contact with each other. The teachers were quite excited by how successful these tools seemed to be, especially with Jeff.

Using these tools really helped some students to communicate how they felt about the music, and seemed to motivate them to communicate directly with each other.

Juliet sat by Jeff throughout the session, and after each song she and I modelled 'I like' and 'do you like?' using the core boards. Jeff followed Juliet pointing to the core board and responded 'Yes' or 'No' to her...Jacob was offered 'Slow' and 'Fast' visuals after he chose 'Kumbaya' and was asked how he would like to play the song. He pointed at the 'Slow' visual.

\section{Visuals (Tempo)}


Visuals depicting changes in tempo (separate to the Core Board so that they were larger and easily seen) were used to enhance the PECs (Bondy \& Frost, 1994) process and improve conversation between students, staff and myself. Participants pointed to the 'faster' or the 'slower' visual to give more detail regarding their choices, likes or dislikes.

\section{Visuals (Photos)}

Photos were presented to the students in order for them to place on the board under 'Here' or 'Not Here'. This enabled them to call the roll at the start of every session and established a routine for the students in this group. These photos were also presented to them to confirm whose turn it was to choose a song. This gave some visual reassurance during the turn taking process.

\section{Technology/Augmentative and Alternative Communication Systems}

\section{iPhone}

I used my iPhone with a non-verbal participant who became frustrated because I was using key signs and singing a particular verse of a song incorrectly. Looking up the correct lyrics and signs on the iPhone, a form of technology that he was very comfortable with, was in an effort to calm the participant and challenge their turn-taking and attention skills.

\section{Music Maker Jam Application (iPhone)}

The Music Maker JAM application on my iPhone (JAM just add music GmbH, 2017) was a tool used as a source of inspiration and/or musical structure in order to make improvisation, recording and songwriting easier to access. It was used to provide accompaniment to drumming exchanges and improvisations, to record pre-composed song and to compose songs using different instrumental 
loops and/or record over these songs. The use of technology often drew the interest and engagement of the students effectively, as per this example:

Ben also enjoys using technology and the Music Maker JAM app. We recorded him drumming and laughing, and when I played it back amongst the other beats he'd chosen he seemed very pleased and nodded his head, grinning, to the music.

\section{Combinations of Forms of Communication}

\section{Musical Communication, Communication through Lyrics and Key Signs from New Zealand Sign Language}

I also used New Zealand Sign Language with the students in certain songs that were conducive to key words. The combination of NZSL, musical communication and communication through the use of lyrics supported the specific classroom learning of particular non-verbal students and gave them and their peers in group sessions another resource with which to socialise. Many students engaged well when key word signs were assigned to certain lyrics or phrases in wellknown songs. The following example describes using sign language in-song with a particular non-verbal student who has limited mobility:

Wes seemed to respond to using sign language in song today. In 'I Can Sing a Rainbow' he touched his face and smiled as I modelled the sign for pink, which is a stroking motion with one finger against your cheek.

Even if a student did not engage physically with the movement of sign language, they would sometimes engage a little more with eye contact or vocalisations when we used NZSL in songs:

'I Can Sing a Rainbow' seemed to grab the attention of students, though they didn't participate in the signing. Wes and Jeff looked directly at me, seemingly engaged as I sang and played guitar...Lucy sang on an 'Mm' occasionally during 'I Can Sing a Rainbow' and smiled. 
One particular non-verbal student would often indicate with signs that he wished me to speed up or slow down songs and we communicated in sign language frequently. He was also able to teach me more signs, as illustrated here:

We used sign language to sing 'I Can Sing a Rainbow' and took turns using signs to contribute animal choices in the song 'I Had a Rooster'. This was an equalizing sort of moment - Ben knows more sign language than I do, and he showed me new signs for particular animals. He also motioned and vocalised for me to put down the guitar and sign and sing with him.

\section{Action Songs - Musical Communication, Communication through Lyrics and Movement}

In order to engage the students with movement I either used familiar songs that already incorporated specific actions/movement or assigned simple movements to familiar songs myself. I used action songs mostly to promote engagement and arm/leg movement, but I also found that fun and engaging actions were often energizing or motivating for students. These action songs were also communicative in that the movements would often covey meaning e.g. extending arms in 'claws' for the lyric 'Roar'.

\section{Actions in Greeting Songs}

I used actions during my pre-composed greeting songs that communicated a greeting, encouraged arm movement and promoted socialisation and interaction. These included actions shaking hands, waving and high-fiving. In some cases I also used these actions in greeting songs to encourage self-regulation and the use of appropriate greeting gestures. Initiation of these greeting gestures by the students themselves, without prompting, was encouraged and became more and more frequent with less mobile students such as Lucy: 
Lucy reached for my hand during the part of the Hello song that says 'Let's shake hands'. This was a significant communicative effort that featured use of lyrics and use of actions.

Using the same actions in this repeated greeting song during every session also provided the students with a sense of structure.

\section{Discussion and Reflection on Written Text/Lyrics}

Lyric discussions were used in order to invite critical and reflective thinking from the student and improve on their conversational and communicative skills. Discussing different interpretations also encouraged emotional expression and/or an understanding of different perspectives. The latter seems to be evident in this example:

We had a go at lyric discussion today. Charlotte commented that she didn't have anything to say about the lyrics of 'Sittin, Waitin' Wishin' or 'Old Fashioned Love Song'. When I asked her about the lyrics of 'Lost Boys', however, she stated immediately that she thought the boy in the song was depressed until Peter Pan had found him, because, as the lyrics say, until then he had never had a family. I wonder whether the storytelling nature of this song prompted Charlotte to be interested in the lyrics, as I know she is an avid reader and loves English and writing. Perhaps the story resonated with her. She might perceive herself as 'different' or feel lonely, and she might see something of herself, 'lost', reflected in the lyrics.

\section{Visual and Musical Communication - Prescriptive Therapeutic Songs using visuals}

Prescriptive therapeutic songs, as discussed earlier, were used in conjunction with visuals with a participant with Down syndrome. This student responded well to visuals accompanying a behavioural message in class- specifically, the visuals helped her to remember a message more clearly. As mentioned previously, this student can have difficulties with self-regulating her behaviour but seemed to greatly enjoy her music therapy sessions. The combination of visuals and prescribed therapeutic songs allowed both visual and musical 
reinforcement of expected behavioural messages. The songs I composed to use with this student included 'Giving back the ukulele' and 'Walking back to class':

Beth is becoming very familiar with her prescribed therapeutic songs, often singing them without prompting and seeming to understand the relevant message conveyed through the lyrics when asked questions about the visuals.

\section{Musical and Social Communication - Toy Play In-Song}

Using toy props in a storytelling style in songs was in an effort to engage students who respond well to play. Specific sound effects and voices are also used to create the playful experience, and participants are encouraged to use the props themselves. The toys also added a visual element to the song, providing structure to a story or sequence of events:

Ashleigh also engaged with the props as we sang 'Five Little Monkeys'. She counted down the number of monkeys left on the bed with ease, and moved them off of the bed one by one during the song. She laughed whenever we sang 'Ouch' as the monkeys hit their head.

Toys were also used as a reward or to encourage arm movement. A particular student refused to walk to the music therapy room and was playing with some coloured balls in his classroom. I used these with him as a reward for choosing a song using PECs (Bondy \& Frost, 1994):

For the last slow-moving song I used some of Wes' balls that he loves to play with and rolled them back and forth between my hands to the rocking rhythm of the song. Wes swayed back and forth, and soon gave me more balls to include.

\section{Techniques Used}

The following findings describe techniques used in my practice in order to facilitate communication. These are not forms of communication in themselves, but are important to discuss in this section as they were implemented for that 
specific purpose and prompted me to reflect substantially during my music therapy practice.

\section{Movement in Songs}

Familiar songs incorporating movement were used with students to encourage engagement, body awareness and the initiation of arm and leg movement. For example, I used movement with a student who had been refusing to walk/stand as he had previously done in order to encourage him to move his feet by marching. Students seemed to engage well with movement songs:

Incorporating movement into more activities with Steven seems to keep him more engaged - I therefore try to keep my music driving and engaging as well, as if it's moving with us.

My use of movement in songs engaged a particular student with Down syndrome well and sometimes seemed to improve her focus. The marching/moving element served as a physical prompt in one of her prescriptive therapeutic songs to encourage her to leave at the end of sessions:

...She laughed as we marched during 'Taxi Time' and this song worked to get her to leaver her classroom at the end of the day. She was also well behaved, giving back the ukulele and walking back to class when asked.

Another movement activity involved the students marching freely to a familiar song that I sang and played on guitar as I had my back to the group. If I stopped playing and turned back around, the students would stop marching and freeze, becoming 'statues'. This musical activity was highly engaging for the students and allowed them to move around freely. I used it frequently to engage students who were a little withdrawn. I also used simple body percussion patterns with students with limited mobility as accompaniment in order to encourage controlled arm movement. 


\section{Easily Accessible Instruments}

I used multiple small instruments (rattle drum, rain-stick, small chimes etc.) that were easy to access with students who had difficulty engaging with or managing instruments appropriately with controlled arm movements. One particular student was fairly uninterested in large instruments such as the piano and guitar, but would engage noticeably more with smaller ones as per this example:

Notable smiling moments where when I handed him the dhurma drum... Jacob didn't engage much with other instruments this session, other than turning the rain-stick over a few times during the Goodbye Song.

\section{Varied Guitar Accompaniment}

I changed my guitar accompaniment so that I was playing energetically and using syncopated, percussive strums in up-tempo songs and using pizzicato in calmer songs. I alternated these strumming patterns to provide musical variety and invite the participants to engage more and express themselves musically. The musical conversation derived from this in turn helped to build the therapeutic relationship:

I implemented a newly learnt strumming pattern today, which was a little more percussive and effective when playing faster. When I changed between strums as Ben prompted me to change dynamics, he grinned and made eye contact with me.

Changing my guitar accompaniment was also in an effort to convey timing changes more easily and offer a sense of containment for the student. This provided a sense of comfort and structure in this example with Charlotte:

I used different strumming patterns throughout to convey the timing changes, which seemed to make the timing clearer for Charlotte as she sang this song with more confidence than she has done before. 
Using a fast, percussive strum with a muted palm technique emphasized the driving march rhythm certain songs, supporting the participant's marching or leg movement along to the beat. This is evident in the following example of work:

I was able to motivate Wes to move his feet and 'march' sitting down with me using a classroom favourite song, When the Saints Go Marching In. I used fast guitar strumming and a muted palm to enhance the rhythm in an attempt to encourage the driving march, which may have encouraged his movement.

\section{Playful Dialogue}

Singing with a child-like, energetic tone and the use of a playful dialogue were used to engage students. An energetic vocal tone was motivating and evoked a sense of play within therapy sessions. It was used particularly with two students who were close friends, students with limited mobility and speech, and students with Down syndrome:

I've found that singing with childlike enthusiasm, and using humour in general in sessions, will often motivate students to engage more (Beth specifically today).

\section{Emphasizing the Beat with Guitar Accompaniment}

Emphasizing the down strum in my guitar accompaniment and vocalisation was in an effort to highlight the beat for the students to play along to and thus make the music more containing:

As we began playing 'Hey Jude', I initially strummed only on the downbeats so that Jessica could settle into drumming the beat. I then strummed the upbeats as well, but kept coming back to an emphasis on the downbeat whenever I felt Jessica needed it.

\section{Emphasizing Suspense with Guitar Accompaniment}


Emphasizing leading notes (such as dominant and major 7ths) highlighted suspense and tension in musical phrasing, and was used to prompt the student to sing/vocalise at appropriate times and improve speech fluidity:

Leaving space and using leading notes/chords to prompt Beth to fill the silence seemed to work well today (on guitar and vocally).

\section{Finger-Picking Guitar Playing}

The use of gentle fingerpicking and arpeggios in my guitar playing was due to its relaxing and non-confronting nature. This style left plenty of space for a participant to engage with instruments and arm movement, expressing themselves at their own pace:

I believe a soft, finger-picking style was appropriate when Lucy was moving to strum the guitar, as it left sufficient space and invited her to strum herself.

I also used this style of playing in new spaces that I was unused to practising in. As these spaces were more public I was more conscious of my practice and/or disturbing others, and thus played quietly and gently:

I sang and played particularly gently and quietly throughout, probably because I was unsure of how loud to be in this new classroom space.

\section{Manipulating the Musical Elements - Dynamics, Tempo and Silence}

I played louder and more intensely during a familiar song as the natural dynamics changes of the piece seemed to help a student self-regulate her emotions. I wondered if emphasizing this might engage her even more and help her to relax:

Jessica enjoys 'I Just Can't Wait to Be King', especially singing loudly along to it as the song builds towards the end. As she was singing she stopped crying, and grinned as she noticed me building the music (louder dynamics, more intense strumming) with her. 
I changed tempo levels to invite participants to 'lead' other musical changes on their own, engage and express themselves musically. In some instances, the tempo changes were 'conducted' by the participants' use of NZSL, though they were mostly indicated musically and/or via body language:

Ben very much enjoyed today when I sped up/slowed down certain songs, such as 'I Can Sing a Rainbow' (which became fun and challenging as he had to sign quickly) and 'I Just Can't Wait to Be King'. He will sometimes slow down/speed up suddenly and make eye contact and I will follow him, and vice versa. I wonder if this is a specific form of communication-listening to each other, growing louder and softer, speeding up and slowing down etc. allows for a communicative exchange between players. He can't tell me verbally to play in any of these ways, but he can with music.

Leaving space at the end of phrases, or on specific accented beats, allowed room for the participant to sing, speak or vocalise the final/emphatic word in the phrase in their own time. I used this technique of manipulating silence or leaving space with students in order to create suspension and prompt the student to respond, thus developing their speech fluidity:

I would pause and leave space for Jeff to either sing or sign during 'I Can Sing a Rainbow'. This worked more frequently at the ends of phrases - for example, Jeff was more likely to sing or sign 'Rainbow' if I did so.

\section{Modelling - Core Board, Drumming, Dynamics, Rhythm and Body Language and Group Tempo and Dynamics}

Staff members and I modelled the use of the Core Board, indicating our likes and dislikes, to invite engagement and support the students' use of the device.

When Jeff chose his first song after the Hello Song, (I Can Sing a Rainbow) using PECs, I showed him the Core Board and modelled pointing to 'I want', then to the I Can Sing a Rainbow visual. He copied me, pointing vaguely to 'want' and saying 'want rainbow'. 
I emphasized my arm movements whilst drumming in an attempt to model drumming to the beat for the participant and invite their initiation of selfregulated arm movement.

Watching me model the drumming allowed him to hone his attention on what his hands were doing and when.

I emphasized my dynamics in my guitar accompaniment in an effort to both model appropriate dynamics levels for the participant in a school setting and prompt their initiation of said dynamics:

... I modelled with my guitar playing what dynamic level she might try. This seemed to work - Ashleigh made an effort to sing when led and adjusted her volume accordingly.

I used body language (nodding my head and emphasizing arm movements) as I accompanied students to emphasize the beat and model how the students might play to it. This provided visual reassurance, containment and support for the students.

I moved my body to the beat, nodding my head, to try and model when they should play.

One group required substantial musical direction in the 'find the instrument' musical cooperation activity. Modelling a fast tempo and loud dynamics when students were close to finding an instrument (and vice versa when they were further away) was used as reinforcement to the group and to invite their own initiation of dynamics and tempo.

\section{Summary of Findings}

The secondary analysis process uncovered a wide variety of forms of communication used in my music therapy practice. These were so varied that different sub-categories of these forms of communication needed to be 
determined: musical communication, social communication, direct instruction, gestures as a tool for communication, key signs from New Zealand Sign Language, verbal communication, technology and augmentative and alternative communication systems and visual forms of communication. A final subcategory, combinations of forms of communication, was determined to highlight specific groupings of forms of communication that became evident during the secondary analysis process. Music therapy techniques used to facilitate communication were also included as important findings. 


\section{Discussion and Limitations}

Before beginning my discussion and outlining the limitations of my work, it is important to note that I have not included a case vignette in this exegesis as is typical in an exegesis of this type. I have chosen not to include this, as I believe the various examples of my clinical notes, reflective journal and research analysis process demonstrate the integration of research and practice effectively.

\section{Discussion of Techniques Used}

\section{Movement in Songs}

Beathard \& Krout (2008), Clerkin (2013) and Meadows (1997) have each described the positive impact of movement with special needs populations. Clerkin (2013) emphasized the importance of movement in energizing special needs participants, while Aldridge et al. (1995a) emphasized the importance of hand movements and gestures in the role of non-verbal communication and emotional expression. The use of movement to maintain or increase fine motor skills was encouraged by Meadows (1997), and I also found it to be successful in my practice.

I used the 'musical statues' movement song not only to encourage movement but as a friendly game in classes where the students were a little older and at the stage where they are engaged by competition. The last student standing in these classes (who listened to the music, watched me and froze/moved accordingly) became the winner. Upon reflection this competition may not have been necessary for the class, but as they requested the activity frequently and seemed engaged I decided not to change that element. 


\section{Playful Dialogue}

The importance of play, fun and games is emphasised in early childhood as they help students develop listening and motor skills, interact musically and understand concepts, among various other benefits (Glover \& Young, 1998). Within the field of music therapy, Beathard and Krout (2008) emphasized the importance of a playful dialogue for creativity and self-discovery with special needs participants, as does McTier (2012). This falls within a creative music therapy approach, also supported by Beathard \& Krout (2008) and Aldridge et al. (1995b). I found playful dialogue and humour to be effective when trying to engage special needs participants in my work. Incorporating a sense of play also allowed me to develop my therapeutic relationship with the students.

\section{Manipulating the Musical Elements - Dynamics, Tempo and Silence}

Reflection on my use of tempo in my practice has led me to the opinion that manipulating the tempo was effective in facilitating musical communication. I found this hypothesis to be supported by Edgerton's work (as cited in Markworth, 2014), as she also found that the manipulation of tempo specifically was used most effectively.

Brief pauses in music, along with hand movements, were effective in motivating the participant to respond or vocalise in Beathard \& Krout's work (2008) The manipulation of musical elements within the special needs population has also been applied to enhance communication skills in this setting (Wang, 2010; Hall, 
2014). As I have developed in my music therapy practice, I have realized just how beneficial the manipulation of musical elements can be in terms of enhancing communication skills.

\section{Discussion of Musical Communication}

\section{Accompaniment}

I believe re-stating this example from earlier in my findings will assist in discussing my use of accompaniment:

The improvisation I had with Rachel was... a bit of a 'wow' moment, really. My supervisor's comments that she wished she'd recorded it for me and that it was a strong example of musical communication really made me feel confident in my skills and, of course, proud of Rachel! We'd improvised on the keyboard, following each other around and calling to each other using short phrases, until she played something that reminded me of Kumbaya and I played an accompaniment and sang to it. I'm unsure as to whether Rachel already knew the melody or whether it was by ear, but she began to play it with me! It was such an amazing moment. We didn't need to talk, we didn't need to sign, and we didn't need to use any visuals. It was just the music, and us and we made a connection there that I'm not sure I can even articulate. This is what it comes down to, for me. I'm a big advocate of using whatever communicative tools I can (that work!) with music therapy, but at the end of the day, music communicates so much on its own, and as a student music therapist especially it should always be my priority.

This particular reflection was, I believe, a pivotal moment in my practice and research process. Up until this point, I had preoccupied myself with the other forms of communication in my practice. Technology, PECs, (Bondy \& Frost, 1994) Sign Language and visuals had each begun to fascinate me in how they might relate to my practice - so much so, in fact, that I fear I neglected the music. I was also self-conscious of my musical skill, and thus thrust my energy into my other endeavours to protect myself from taking any risks. This improvisation and the accompaniment derived from it brought me back to a realisation of what 
music and music therapy can accomplish - free flowing conversation that can transcend language and ability.

\section{Requested Songs}

In one instance, a particular student was becoming uninterested during familiar songs, so I asked her to choose the next song for us in order to re-engage her in the session. In honesty, I had also grown tired and forgotten which song/activity I had planned to do next, so asking her to choose took that responsibility from me. I intend to recognise instances such as this one more often in the future in order to improve my practice further.

\section{Familiar Songs}

When describing the use of familiar songs in my findings, I intended to use the following example:

During the bridge of 'Hey Jude' Jessica became excited and her singing became louder and more energised. This is quite a motivating and energizing song that she seems to enjoy singing.

Upon reflection, I am not so sure that the fact that 'Hey Jude' was a familiar song to Jessica was why she found it so engaging. The refrain at the end of this particular song features a driving rhythm and catchy, almost-chant-like melody. This was likely what engaged Jessica. Familiar songs can certainly be effective in music therapy practice, as demonstrated in the literature (Walworth, 2003; Dassa, 2014). I wonder whether I sometimes overlooked other reasons as to why students might be so excited by them at times. 
In addition, it is important to note that I used familiar songs when my own energy in my practice was depleted. As these songs soon became familiar to me, they were easy to play and share with the students. At times it definitely felt as if I played familiar songs due to a lack of inspiration as to what to do next, as per this example:

I would say that by this point in the day, after an eventful group and supervision, I had definitely become exhausted. I hope Ashleigh's session was still beneficial. Next week I intend to do more musically with her rather than just 'going from song to song'.

\section{Greeting/Farewell Songs}

In my practice, I used a repeated greeting song to signal the beginning of a session and a goodbye song to communicate a farewell. The use of Hello and Goodbye songs in music therapy with students with special needs is supported in the literature (Clerkin, 2013; Beathard \& Krout, 2008). Kern, Wolery \& Aldridge (2007) utilised songs in morning greeting routines that were individually composed for each child. I, however, (as a beginning practitioner) used two specifically pre-composed songs (one to greet, the other to say goodbye) instead of composing them specifically for each child. I adapted the songs over time to allow the students to respond to me vocally, as initially we were simply singing the lyrics together. I implemented this after reading that brief pauses or prompts used in a greeting song could be used to prompt verbalisation (Beathard \& Krout, 2008).

\section{Drum Circle Song - Lyric Request}

In the drum circle song, I intended to implement the lyrics as a request. In honesty, the lyrics were instead implemented as a signal, and the students were 
usually expected and encouraged to drum. I see this now as an opportunity to improve my practice. If I use this song in the future, I might allow for a response phrase in which the student can agree or decline to play. Leaving space to allow for a response such as this is exemplified in Beathard \& Krout's (2008), and could be beneficial in encouraging verbalisation.

\section{Joint Songwriting}

In my findings I reported on the intervention of joint songwriting with two students, Diego and Charlotte. Throughout my practice, I constantly questioned whether or not these two very different students (one occasionally withdrawn and anxious, one high-functioning and at times inflexible) should have separate music therapy sessions. In group sessions, a music therapist can move the musical control between themselves, a particular student or an entire group, allowing them to give different students varying levels of control throughout sessions (which could prove challenging or rewarding) (Carter \& Oldfield, 2015). Encouraging sharing and compromise of songwriting and musical control was important to challenge Charlotte, and Diego may not have initially participated in sessions if he was alone. Perhaps both individual and joint sessions might have been more appropriate for these students in order to challenge Charlotte and build Diego's confidence.

\section{Group Singing and Songwriting}

As I developed my practice I learned to introduce songwriting at the start of sessions (when the groups were energized and focused) and keep the activity short, as otherwise the classes could become restless: 
Some students grew restless and others bored during the songwriting session, so I kept it quite short. Charlotte seemed to enjoy contributing and asked others their opinions as well.

When the songs were written, the groups and I would often sing them together. I found it to be a lovely way to encourage interaction between the classmates. Perry (2003) found group singing, such as this, to be beneficial for communication skills with severely and multiple disabled children.

\section{Songwriting via keyboard improvisation}

As discussed in my findings, an improvisation on the keyboard with a particular student eventually evolved into a song. Afterwards, I reflected on the songwriting process. I wondered whether it was necessary to evolve the exchange from improvisation and whether I was too focused on the 'purpose' of the song:

After that improvisation, I wondered whether I needed to turn Ashleigh's improvisation into a song. We both enjoyed what we played together and Ashleigh engaged happily with it, but I wonder whether by introducing the 'counting' purpose and giving it more structure I was trying to use my teacher 'hat' more than my therapist one. And maybe that's ok? If teaching fits in with therapy goals, putting the teacher 'hat' on could work...but maybe I should have just improvised with Ashleigh? It's difficult to say.

It seems worthwhile noting here that songs derived from improvisation are a common occurrence within music therapy (Baker, Oldfield \& Magill, 2005). My concern here is that the song, which eventually focused on counting and learning, might have fallen into the realm of teaching rather than therapy. I will discuss the role of teaching in music therapy later in my discussion.

\section{Drumming exchange - Copying rhythms and Turn taking}


The drumming exchange that I facilitated with Steven on the bongos illustrated how taking turns encouraged arm movement and self-regulation. Bell, Perry, Peng \& Miller (2014) discussed turn taking in their work, stating that music therapists use turn-taking activities for children with ASD specifically to encourage communication and social interaction. Perry (2003) also found turn taking to be beneficial in aiding communication skills with this population, and Clerkin (2013) found following and leading to be a successful tool in their practice.

\section{Discussion of Musical and Visual Communication}

\section{Prescriptive Therapeutic Songs With and Without Visuals}

As reported earlier, I used prescriptive therapeutic songs (with and without visuals) with students in order to target specific behaviours. During my practice and in my analysis, I labelled these as 'Social Story Songs'. I have since come to realise that this label is inappropriate. Though I had been exposed to Social Stories $^{\mathrm{TM}}$, I had not yet done research into the specifics of how to apply them and their use in music therapy.

Musically adapted social stories proved beneficial in reducing or modifying targeted behaviours in students with autism in Brownell's (2002) case study. As described earlier, Social Stories ${ }^{\mathrm{TM}}$ involve integrating an autistic individual's inclination for success in visual learning with behaviour modifications that were necessary for their education and development. Pasiali's (2004) similar method of implementing prescriptive therapeutic songs to reduce target behaviours with autistic children involved 'piggybacking' familiar melodies to accompany the lyrics of an individually composed social story and using a visual schedule of 
sessions to provide structure. Rickson (2010) also used musically adapted social stories that featured lyrics adapted using Social Stories ${ }^{\mathrm{TM}}$ guidelines. Song lyrics associated with melodies, according to Rickson, are easier for individuals to learn than a speech. Rickson also asserted that it was important to draw on the experience of her colleagues when using musically adapted social stories.

I was uninformed about Social Stories ${ }^{\mathrm{TM}}$ before beginning to use a similar process in my work. The lyrics I composed (sometimes accompanying visuals and sometimes not) did not necessarily follow the descriptive, directive, perspective and control sentence types required. I acknowledge that labelling an intervention such as Social Stories ${ }^{\mathrm{TM}}$ incorrectly could result in diminishing the value of the method, and thus altered my label from 'Social Story Songs' to 'Prescriptive Therapeutic Songs'.

\section{Discussion of Musical and Social Communication}

\section{Toy Play In-Song}

As mentioned previously, play and a creative approach to music therapy in special needs populations is supported by the literature (Beathard \& Krout, 2008; McTier, 2012; Aldridge et al., 1995b). Thompson \& McFerran (2015) found that music therapy proved more successful in facilitating interpersonal and communicative encounters between therapist and participant than toy play with special needs participants. This suggests that musical intervention might be more beneficial than the non-musical toy play evident in my work. However, I suggest that using both interventions together can add a sense of playfulness and encourage engagement from the participant/s. The use of toys, books, drawings, bubbles and other props was found to have been effective when used alongside 
music therapy by Beathard \& Krout (2008). I certainly found the use of toy play within a musical context to be highly beneficial. As per my examples in my findings, using toys in song encouraged movement, provided visual accompaniment to songs and heightened engagement. I do not doubt Thompson \& McFerran's (2015) findings in that music therapy might be more beneficial than toy play in and of itself, but propose that an integration of the two can be successful, especially in this setting.

\section{Intensive Interaction}

I was unaware of Intensive Interaction until a speech therapist introduced it in one of my group sessions (thus why it is not included in the literature review). However, it proved to be a valuable resource in practice. As discussed during my findings, Intensive Interaction is the response of an individual's body language and facial expressions using playful imitation (Ephraim, 1986 cited in Culham, 2004 and Caldwell, 2006). My use of Intensive Interaction (more specifically, imitating students' movements and body language) to support socialisation and interaction in the classroom seemed to be supported by Caldwell's work (2006) in which Intensive Interaction was used successfully to improve social and communication skills in young autistic people. How's work (2014) also supported this, and Tomlinson (2012) suggested that imitation could be a powerful tool to enhance communication. It seems important to note that the key principles of Intensive Interaction seem to echo key principles of music therapy. Mirroring a musical offering from a participant benefits communication by allowing musical conversation, providing comfort and support, and promoting 
sharing and expression. In my practice, I tried to match my vocal and guitar phrasing to the students' movements, toy play, energy levels and/or musicality:

I tried to match my strumming on guitar in 'I'm a Believer' to Wes' bouncing and swaying, and tried to make my playing quite energetic. He continued to roll the balls back and forth, move around his sensory toys and bounce/sway.

My introduction of Intensive Interaction from the facility's speech therapist highlights how important collaboration is in this work. I would also suggest that the use of Intensive Interaction in song definitely increased engagement. Daniel, the particular student in my example (discussed in my findings) often showcased echolalia and sometimes struggled with communication. The prospect of having his own movements repeated back to him by his classmates and myself was particularly exciting for him, and he was able to communicate with the group via his contribution.

\section{Discussion of Augmentative and Alternative Communication}

\section{Systems}

\section{iPhone and Music Maker JAM Application}

Alternative communication devices were found to be effective when examining the literature (Hall (2014). Gadberry (2011) in fact suggests that the use of Augmentative and Alternative Communication systems (AAC) is not only beneficial among special needs participants but in many cases, necessary. In my practice I was mostly able to access my personal iPhone, though I occasionally used conversation applications on particular students' iPads in order to 
communicate with them. Xin \& Leonard's work (2014) makes reference to the iPad, claiming that students who were given access to the device improved their communication skills. The iPhone is significantly smaller than the iPad, and I thus acknowledge its limitations in that a) it was more difficult for students to access physically and visually and b) they were unfamiliar with the device. It did, however, serve well when using the Music Maker JAM application (JAM just add music GmbH, 2017). This was used to compose songs, record and provide accompaniment to drumming exchanges and improvisations. I found this application particularly useful when a student was withdrawn and difficult to engage. The introduction of technology would often excite them and they would once again become interested in music making. It also allowed for accessibility to many different sounds that we were unable to create ourselves using acoustic instruments.

\section{PECs and Visuals}

Using The Picture Exchange Communication System (Bondy \& Frost, 1994) was one of my most common AAC interventions in my practice. I found the system to be an effective tool in facilitating choice, a finding supported by Lancioni et al. (2007) and Beathard \& Krout (2008). Song choices were also one of the most common interventions used by music therapists working with clients with ASD in Kaplan and Steele's (2005) analysis. Visuals and symbols were found to be effective in Hall's (2014) and Beathard \& Krout's (2008) work. Furthermore, using educational supports such as written words, colour coding, icons, echoing, the buddy system and other visual aids were found to be beneficial in teaching those with special needs (Whipple \& VanWeelden, 2012). 


\section{Discussion of Sign Language - Key Signs from NZSL}

My use of key signs to encourage communication is supported in Beathard \& Krout's (2008) case study, although I recognise that that American Sign Language was used here rather than New Zealand Sign Language and that they are independent of each other. I also recognise that New Zealand Sign Language is part of Deaf culture, and that language and culture are interdependent (Ministry of Education, 2006). I understand that consultation with d/Deaf communities when teaching/using NZSL is recommended so as not to offend users of the language with error or misuse. I thus attended classes and consulted with the appropriate teachers and students at the centre. I also recognise that key signs do not reflect the entirety and complexity of New Zealand Sign Language. In my practice I found the use of key signs in-song to be highly effective in encouraging engagement and improving communication skills with those acquainted with the language. After further reading, I discovered that the integration of music and sign language has the potential to strengthen the communicative benefits of both (Schunk, 1999).

\section{Discussion of Direct Instruction}

Kaplan and Steele's (2005) analysis of programme goals revealed that interactive instrument playing and musical instrument instruction were some of the most common interventions used by music therapists working in this field. Meadows (1997) also described an educational orientation within music therapy, in which emphasis is placed on developmental or curricular goals. Earlier, I discussed my hesitancy in putting on my 'teaching hat' in a specific example, fearful that it would encroach upon therapeutic principles. However, upon further reading I 
have been reassured that, as appropriate, the integration of musical education and music therapy with special needs students can benefit students' development and wellbeing (Darrow, 2013). Though the general principle of music therapy is to address non-musical goals, working as a co-therapist with special educators can provide a student with the most comprehensive services available. After the conclusion of therapy, an interest and participation in music could also serve to make the transition from the classroom to the community a little easier. An integration of music education within music therapy could help to accomplish this. (Darrow, 2013). As long as a student is interested in musical learning and it proves to be a rewarding experience for them, there seems to be no reason why it cannot be included in a therapeutic context. In my practice, I also found that direct instruction could build self-esteem by elevating a sense of mastery on a favourite instrument.

\section{Approach}

As a student music therapist, my music therapy approach is constantly developing. The examined literature uncovered various approaches used in special needs contexts, including creative, behavioural (Beathard \& Krout, 2008; Meadows, 1997), recreational, healing (Meadows, 1997) and educational (Whipple \& VanWeelden, 2012). The two most supported by the literature relating to special needs settings, however, are improvisational and childcentred. I find that I predominantly identify with these approaches in my work.

Bayes et. al. (2013) stressed that nurturing to a child's individuality is necessary in this setting, supporting the call for a child-centred approach. Nordoff \& 
Robbins (1965) emphasized the importance of improvisational and musiccentred music therapy for autistic children. Hall, (2014) Savaiinaea, (2009) and Wang (2010) found that improvisation was beneficial in the experience of enhancing communication when working with children in schools with learning difficulties, and Simpson \& Keene (2011) found that improvisational music therapy was one of the most common interventions used in their review.

In my practice, I found that improvisation encouraged engagement, musical expression, communication and arm movement. This also served to build selfesteem and confidence. Although the use improvisation does not constitute an entire approach, it was utilised frequently and I believe it was the basis of therapeutic progress with many students.

\section{Music as Therapy and Music in Therapy}

Relating my findings and discussion back to music as therapy and music in therapy, I found myself struggling to identify with either concept. The various tools and forms of communication I used in my practice, when integrated with music, usually proved to be beneficial in developing communication skills. It seems as if two methods used together (for example, visual and musical communication) can sometimes accomplish more than one alone. One of my most poignant reflections in my work, however, was that, as a music therapist, music should always be my primary therapeutic tool. If I were to categorize my current approach to my music as 'music in therapy' or 'music as therapy', I believe I would describe it as the latter. However, I do not believe that music 
need necessarily be the only form of communication used, especially not with special needs populations. This is similar to Oldfield's (2006) position on the matter. A focus on music informed by visuals, AAC systems, sign language, playful dialogue and any other form of communication that proves beneficial is, I believe, the most applicable in this setting. 


\section{Conclusion}

In conclusion, my research analysis revealed various forms of communication and techniques to aid communication that were used in my therapy practice with special needs students. Categorising and labelling these proved to be difficult, as often one form of communication would overlap with another when describing a particular intervention. This seems to indicate not only were a variety of forms of communication used in my practice, but also that I often used more than one at a time. Communication is a complex human endeavour. Drawing out specific aspects of the communication naturally results in simplistic findings. While acknowledging that communication is much more complex, the analysis has enabled me to make explicit some of the more dominant forms of communication that I used in my work. This information is likely to be useful and interesting to people who are new to music therapy. Musical communication was used for a variety of reasons, including: to encourage communication, engagement, the initiation of eye contact, vocalisations and movement, choice-making, turntaking, expression, teamwork and relaxation; to support socialisation, interaction, self-regulation, focus, confidence, self-esteem and connections between culture and the community; to develop musicianship, memory, leadership and fine motor skills and to establish greetings and routine and reinforce behavioural messages. Social communication was used to encourage engagement, vocalisation, eye contact and hand movement and to support communication, socialization and interaction. I used direct instruction to improve musicianship, speech, motor and communication skills and to build confidence and self-esteem. Gestures were used to engage, build the therapeutic 
relationship and support the initiation of arm movement and Key Signs from New Zealand Sign Language were used to encourage engagement, facilitate communication and support classroom learning and arm movement. Verbal communication was used to support conversation and encourage choice making. Visual communication, including the use of PECs, (Bondy \& Frost, 1994) was used to prompt, provide structure, encourage choice-making, turn-taking and arm movement and to promote self-regulation and expression. Finally, technology and Augmentative and Alternative Communication devices were used to encourage engagement, focus, turn taking and relaxation and to provide structure and inspiration using accompaniment, recording or composition tools. I discovered that the integration of these forms of communication often proved more effective than one at a time in addressing the needs of these special needs students, but also acknowledge that music could be a highly effective therapeutic tool on its own. I thus conclude that integrating a variety of forms of communication into my music therapy practice (whilst keeping a focus on music therapy, improvisation and the individual child) supported my work in a special needs educational setting. 


\section{References}

Adamek, M. S. \& Darrow, A. A. (2005). Music in special education. Silver Spring, MD: American Music Therapy Association

Aigen, K. (2005). Music-centered music therapy (Kindle ed.). Gilsum, N.H.: Barcelona. Aigen, K. S. (2014a). Music-centred dimensions of Nordoff-Robbins Music Therapy. Music Therapy Perspectives, 32(1), 18-29.

Aigen, K. S. (2014b). The study of music therapy: Current issues and concepts. New York, NY: Routledge.

Aldridge, D., Gustorff, D., \& Neugebauer, L. (1995a). A pilot study of music therapy in the treatment of children with developmental delay. Complementary Therapies in Medicine, 3, 197-205. doi: 10.1016/S0965-2299(95)80072-7

Aldridge, D., Gustorff, D., \& Neugebauer, L. (1995b). A preliminary study of creative music therapy in the treatment of children with developmental delay. The Arts in Psychotherapy, 22(3), 189-205.

Allen, T. E., Letteri, A., Choi, S. H., \& Dang, D. (2014). Early visual language exposure and emergent literacy in preschool deaf children: Findings from a national longitudinal study. American Annals of the Deaf, 159(4), 346-358. doi: 10.1353/aad.2014.0030

American Psychiatric Association. (2013). Diagnostic and statistical manual of mental disorders (DSM - 5) (5 th $^{\text {th }}$ ed). Arlington, VA: American Psychiatric Publishing.

Baker, F., Oldfield, A., \& Magill, L. (2005). Songwriting; Methods, Techniques and Clinical Applications for Music Therapy Clinicians, Educators and Students. London, GB: Jessica Kingsley Publishers 
Bayes, D. A., Heath, A. K., Williams, C., \& Ganz, J. B. (2013). Pardon the interruption. Teaching Exceptional Children, 45(3), 64-70.

Beathard, B., \& Krout, R. E. (2008). A music therapy clinical case study of a girl with childhood apraxia of speech: Finding Lily's voice. The Arts in Psychotherapy, 25, 107-116. doi: 10.1016/j.aip.2008.01.004

Bell, A. P., Perry, R., Peng, M., \& Miller, A. J. (2014). The Music Therapy Communication and Social Interaction Scale (MTCSI): Developing a new Nordoff Robbins scale, and examining interrater reliability. Music Therapy Perspectives, $32(1), 61-70$.

Bondy, A. S., \& Frost, L. A. (1994). The Picture Exchange Communication System. Focus on Autism and Other Developmental Disabilities, 9(3), 1-19. doi: $10.1177 / 108835769400900301$

Braun, V., \& Clarke, V. (2006). Using thematic analysis in psychology. Qualitative Research in Psychology, 3(2), 77-101. doi: 10.1191/1478088706qp063oa

Brownell, M. K. (2002). Musically adapted social stories to modify behaviors in students with autism: Four case studies. Journal of Music Therapy, 39, 117-144. doi: $10.1093 / \mathrm{jmt} / 39.2 .117$

Bruscia, K. E. (1987). Improvisational models of music therapy. Springfield, IA: CC Thomas.

Bruscia, K. E. (1998). The dynamics of music psychotherapy. Phoenixville, PA: Barcelona Publishers.

Bunt, L., \& Stige, B. (2014). Music therapy: An art beyond words (2 ${ }^{\text {nd }}$ ed.). East Sussex, England: Routledge.

Caldwell, P. (2006). Speaking the others language: Imitation as a gateway to relationship. Infant and Child Development, 15, 275-282. 
Carter, E., \& Oldfield., A. (2015). A music therapy group to assist clinical diagnoses in child and family psychiatry. In A Davies \& E Richards (Eds.), Music Therapy and Group Work: Sound Company (pp. 149 - 163). London, England: Jessica Kingsley Publishers.

Clements-Cortes, A. (2013). High-tech therapy: music technology in music therapy. Canadian Music Educator, 54(4), 37+. Academic OneFile, go.galegroup.com/ps/i.do?p=AONE\&sw=w\&u=vuw\&v=2.1\&id=GALE\%7CA3347 10252\&it=r\&asid=836d9213cdbdd2a41cba7df7f55e2f56. Accessed 10 Jan. 2017.

Clerkin, C. (2013). Beyond imitation, without limitations: A student music therapist supports the participation and development of young people with profound and multiple learning difficulties in a school setting (Exegesis, Massey University and Victoria University of Wellington, Wellington, New Zealand). Retrieved from http://researcharchive.vuw.ac.nz/handle/10063/2755

Culham, A. (2004). Getting in touch with our feminine sides? Men's difficulties and concerns with doing Intensive Interaction. British Journal of Special Education, 31(2), 81-88.

Darrow, A. (2013). Music therapy and special music education: Interdisciplinary dialogues. (G. Tsiris, Interviewer). Approaches: An Interdisciplinary Journal of Music Therapy, 5(1), 12-17.

Dassa, A. (2014). The role of singing familiar songs in encouraging conversation among people with middle to late stage Alzheimer's disease. Journal of Music Therapy, 51(2), 131-153.

Gadberry, A. L. (2011). A survey of the use of aided Augmentative and Alternative Communication during music therapy sessions with persons with Autism 
Spectrum Disorders. Journal of Music Therapy, 48(1), 74-89. doi:

$10.1093 / \mathrm{jmt} / 48.1 .74$

Gadberry, A. L. (2012). Client communicative acts and therapist prompts with and without aided Augmentative and Alternative Communication systems. Music Therapy Perspectives, 30(2), 151-157. doi: 10.1093/mtp/30.2.151

Geretsegger, M., Holck, U., Carpente, J. A., Elefant, C., Kim, J., \& Gold, C. (2015).

Common characteristics of improvisational approaches in music therapy for children with Autism Spectrum Disorder: Developing treatment guidelines. Journal of Music Therapy, 52,(2), 258-281.

Glass, G. V. (1976). Primary, secondary, and meta-analysis of research. Educational Researcher, 5(10), 3-8. doi: 10.2307/1174772

Glover, J., \& Young, S. (1998). Music in the early years. Retrieved from https://ebookcentral.proquest.com

Graham, J. (2004). Communicating with the uncommunicative: music therapy with preverbal adults. British Journal of Learning Disabilities, 32, 24-29.

Grove, N. \& Walker, M. (2009). The Makaton vocabulary: Using manual signs and graphic symbols to develop interpersonal communication. Augmentative and Alternative Communication, 45(1), 15-28. doi:

$10.1080 / 07434619012331275284$

Guilluy, P. (2016). Beatbox Looper (Version 1.2) [Mobile application software]. Retrieved from https://itunes.apple.com/au/app/beatboxlooper/id736665964?mt=8

Hahna, N. D., Hadley, S., Miller, V. H., \& Bonaventura, M. (2012). Music technology usage in music therapy: A survey of practice. The Arts in Psychotherapy, 39(5), 456-464. 
Hall, S. (2014). Coming up trumps: A student music therapist supports young people with high or very high complex special needs to develop the key competencies (Exegesis, Massey University and Victoria University of Wellington, Wellington, New Zealand). Retrieved from http://researcharchive.vuw.ac.nz/handle/10063/4641

How, S. H. (2014). Interaction within the therapeutic relationship: Exploring the relationship between the music therapy practices of a music therapy student and the concepts used in Intensive Interaction. . (Thesis dissertation, Massey University and Victoria University of Wellington, Wellington, New Zealand). Retrieved from http://researcharchive.vuw.ac.nz/bitstream/handle/10063/3729/thesis.pdf?se quence $=2$

Intensive Interaction Institute (2017). How does Intensive Interaction work - what do you do? Retrieved from http://www.intensiveinteraction.co.uk/about/howdoes-intensive-interaction-work/

JAM just add music GmbH (2017). Music Maker JAM: Create, remix and share your music! (Version 3.4.1) [Mobile application software]. Retrieved from https://itunes.apple.com/us/app/music-maker-jam-createremix/id880929886? $\mathrm{mt}=8$

Joseph, R., \& Tager-Flusberg, H. (2009). Face and gaze processing in autism. In T. Striano \& V. Reid (Eds.), Social cognition: Development, Neuroscience, and Autism (pp. 201-215). West Sussex, UK: Wiley-Blackwell

Kalas, A. (2012). Joint attention responses of children with Autism Spectrum Disorder to simple versus complex music. Journal of Music Therapy, 49(4), 430-452. 
Kaplan, R. S., \& Steele, A. L. (2005). An analysis of music therapy program goals and outcomes for clients with diagnoses on the Autism spectrum. Journal of Music Therapy, 42(1), 2-19.

Kern, P., Wolery, M., \& Aldridge, D. (2007). Use of songs to promote independence in morning greeting routines for young children with autism. Journal of Autism and Developmental Disorders, 37(7), 1264-1271. doi: 10.1007/s10803-006-0272-1

Kim, J., Wigram, T., \& Gold, C. (2008). The effects of improvisational music therapy on joint attention behaviours in autistic children: A randomized controlled study. Journal of Autism and Developmental Disorders, 38(9). 1758-1766. doi:

$10.1007 / \mathrm{s} 10803-008-0566-6$

Kim, J., Wigram, T., \& Gold, C. (2009). Emotional, motivational and interpersonal responsiveness of children with autism in improvisational music therapy. Autism, 13(4), 389-409.

Knight, A. (2013). Use of iPad® applications in music therapy. Music Therapy Perspecitives, 31(1),189-196.

Lancioni, G. E., O’Reilly, M. F., Cuvo, A. J., Singh, N. N., Sigafoos, J., \& Didden, R. (2007). PECS and VOCAs to enable students with developmental disabilities to make requests: An overview of the literature. Research in Developmental Disabilities, 28(5), 468-488. doi: 10.1016/j.ridd.2006.06.003

Malloy, T. V. (2003). Sign language use for Deaf, hard of hearing, and hearing babies: The evidence supports it. American Society for DeafChildren. Retrieved from http://www.gallaudet.edu/Images/Clerc/pdf/Full\%20Document\%20of\%20ASD C\%20Sign\%20Language\%20for\%20All-English.pdf

Markworth, L. (2014). Without words: Music as communication for children with autism. Qualitative inquiries in music therapy, 9, 1-4. 
McTier, I. S. (2012). Music therapy in a special school for children with Autistic Spectrum Disorder, focusing primarily on the use of the double bass. In J. Tomlinson, P. Derrington \& A. Oldfield (Eds), Music therapy in schools: Working with children of all ages in mainstream and special education (pp 151-164). London, UK: Jessica Kingsley Publishers.

Meadows, T. (1997). Music therapy for children with severe and profound multiple disabilities: A review of the literature. The Australian Journal of Music Therapy, 8, 3-17.

Ministry of Education. (2006). New Zealand Sign Language in the New Zealand Curriculum. Retrieved from:

http://ndhadeliver.natlib.govt.nz/delivery/DeliveryManagerServlet?dps_pid=IE 759106

Ministry of Education (2010). The New Zealand Deaf Community. Retrieved from http://www.tki.org.nz/r/language/curriculum/nzsl/community/index_e.html Ministry of Education. (2011). Collaboration for success: Individual Education Plans. Wellington: Learning Media

Ministry of Education. (2016). Overview of Ongoing Research Scheme (ORS). Retrieved from http://www.education.govt.nz/school/student-support/specialeducation/ors/overview-of-ors/

Music Therapy New Zealand. (2012). Code of Ethics for the Practice of Music Therapy in New Zealand. Music Therapy New Zealand. Retrieved from http://www.musictherapy.org.nz/wpcontent/uploads/downloads/2013/02/Code-of-Ethics-2012.pdf 
New Zealand School of Music. (2015). Music Therapy Department, Master of Music Therapy Programme: Ethical Guidelines for NZSM526 Research Projects.

Wellington, New Zealand: New Zealand School of Music.

Nordoff, P., \& Robbins, C. (1965). Improvised music for autistic children. Music Journal, 23(8), $39 \& 67$.

Nordoff, P., Robbins, C. (1977). Creative music therapy: Individualized treatment for the handicapped child. New York, NY: The John Day Company.

Oldfield, A. (2006). Interactive music therapy-a positive approach. London, UK: Jessica Kingsley Publishers.

Pasiali, V. (2004). The use of prescriptive therapeutic songs in a home-based environment to promote social skills acquisition by children with autism: Three case studies. Music Therapy Perspectives, 22(1), 11-20. doi:

$10.1093 / \mathrm{mtp} / 22.1 .11$

Paul, P. V., \& Lee, C. (2010). The qualitative similarity hypothesis. American Annals of the Deaf, 154(5), 456-462

Perry, M. M. R. (2003). Relating improvisational music therapy with severely and multiply disabled children to communication development. Journal of Music Therapy, 40(3), 227-246. doi: 10.1093/jmt/40.3.227

Petitto, L. A., \& Marentette, P. F. (1991). Babbling in the manual mode: Evidence for the ontogeny of language. Science, 251(5000), 1493-1496.

Raising Children Network (2017). Social Stories ${ }^{T M}$. Retrieved from http://raisingchildren.net.au/articles/social_stories_th.html

Rickson, D. J. (2010). The development of a music therapy school consultation protocol for students with high or very high special education needs. (Doctoral thesis, New Zealand School of Music, Wellington, New Zealand). Retrieved from 
http://researcharchive.vuw.ac.nz/bitstream/handle/10063/1477/thesis.pdf?se quence $=1$

Savaiinaea, C. M. (2009). Challenges in communication: A critical analysis of a student music therapist's techniques in working with special needs children. (Thesis dissertation, Massey University and Victoria University of Wellington, Wellington, New Zealand). Retrieved from http://researcharchive.vuw.ac.nz/handle/10063/1082

Schuler, A. Prizant, B. M., \& Wetherby, A. M. (1997). Enhancing language and communication development: Prelinguistic approaches. In D. J. Cohen \& F. R. Volkmar (Eds.), Handbook of autism and pervasive developmental disorders $\left(2^{\text {nd }}\right.$ ed., pp. 539-571). New York: Wiley.

Schunk, H. A. (1999). The effect of singing paired with signing on receptive vocabulary skills of elementary ESL students. Journal of Music Therapy, 36, 110124.

Shane, H. C., Laubscher, E. H., Schlosser, R. W., Flynn, S., Sorce, J. F., \& Abramson, J. (2012). Applying technology to visually support language and communication in individuals with Autism Spectrum Disorders. Journal of Autism and Developmental Disorders, 42(6), 1228-1235. doi: 10.1007/s10803-011-1304-z

Simpson, K., \& Keen, D. (2011). Music interventions for children with Autism: Narrative Review of the Literature. Journal of Autism and Developmental Disorders, 41(11), 1507-1514. doi: 10.1007/s10803-010-1172-y

Stern, D. (1977). The first relationship. London: Fontana/Open Books Publishing Limited.

Stern, D. (1985). The interpersonal world of the infant. New York: Basic Books 
Strange, J. (2012). Psychodynamically informed music therapy groups with teenagers with severe special needs in a college setting: Working jointly with teaching assistants. In J. Tomlinson, P. Derrington \& A. Oldfield (Eds), Music therapy in schools: Working with children of all ages in mainstream and special education (pp 179-193). London, UK: Jessica Kingsley Publishers.

Straus, J. N. (2014). Music therapy and Autism: A view from disability studies. Voices: A World Forum for Music Therapy, 14(3). doi:10.15845/voices.v14i3.785

Thompson, G. A., \& McFerran, K. S. (2015). Music therapy with young people who have profound intellectual and developmental disability: Four case studies exploring communication and engagement within musical interactions. Journal of Intellectual and Developmental Disability, 40(1), 1-11. doi:

$10.3109 / 13668250.2014 .965668$

Tomlinson, J. (2012). Music therapy in a special school: Investigating the role of imitation and reflection in the interaction between music therapist and child. In J. Tomlinson, P. Derrington \& A. Oldfield (Eds), Music therapy in schools: Working with children of all ages in mainstream and special education (pp 103-115). London, UK: Jessica Kingsley Publishers.

Vaismoradi, M., Turunen, H., \& Bondas, T. (2013). Content analysis and thematic analysis: Implications for conducting a qualitative descriptive study. Nursing \& Health Sciences, 15. 398-405.

Victoria University of Wellington. (n.d.). Human ethics policy: Research policy group. Victoria University of Wellington. Retrieved from http://www.victoria.ac.nz/documents/policy/research-policy/human-ethicspolicy.pdf

Waldman, H. (2001,). When young hands do the talking. The Hartford Courant. 
Walworth, D. D. (2003). The effect of preferred music genre selection versus preferred song selection on experimentally induced anxiety levels. Journal of Music Therapy, 40, 2-14.

Wang, A. (2010). Musical analysis of clinical improvisations with an adolescent who has communication difficulties. (Exegesis, Massey University and Victoria University of Wellington, Wellington, New Zealand). Retrieved from http://researcharchive.vuw.ac.nz/handle/10063/1547

Whipple, C. M., Gfeller, K., Driscoll, V., Oleson, J., \& McGregor, K. (2015). Do communication disorders extend to musical messages? An answer from children with hearing loss or Autism Spectrum Disorders. Journal of Music Therapy, 52(1), 78-116. doi: 10.1093/jmt/thu039

Whipple, J., \& VanWeelden, K. (2012). Educational supports for students with special needs: Preservice music educators' perceptions. Update: Applications of Research in Music Education, 30(2), 32-45. doi: 10.1177/8755123312436987

Wilkinson, K. M., \& Hennig, S. (2007). The state of research and practice in augmentative and alternative communication for children with developmental/intellectual disabilities. Mental Retardation and Developmental Disabilities Research Reviews, 13(1), 58-69. doi: 10.1002/mrdd.20133

Xin, J. F., \& Leonard, D. A. (2014). Using iPads to teach communication skills of students with Autism. Journal of Autism and Developmental Disorders, 45(12), 4154-4164. doi: 10.1007/s10803-014-2266 


\section{Appendices - Appendix A}

The following example of my research analysis relates to my use of accompaniment as a form of musical communication. Pseudonyms are used, and the colour coding corresponds to individual students for my personal reference.

Cotegory of communication
Codin

Notes

Recoding

Themes - Findings and Discussion

I used a simple arpeggiated ccompaniment on the lower half of keyboard to support the

27-Jul Musical (keyboard)

23-Aug Musical keyboard)

Accompaniment (vocal,

30-Aug Musical eyboard)

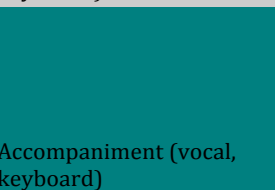

improvisation structure odies and finger olation and provide structure
Support playing, support improvisation finger isolation, structure
After hearing repeated major thirds in the improvisation from the Kumbaya, and accompany it. The supporting initiation, aural skills, Communication, su with me. memory skills, fine motor skills

Participant played melodies by ear on keyboard that I sang as I
accompanied in bottom half o Communication, engagement, Communication, su keyboard to support her initiatio supporting initiation, memory skils, fraction, aural skills,

I sang short, simple melodies and used a simple arpeggiated

Support mprovisation,
finger isolation inger isolation
structure of the keyboard to support the

student's improvisation and fing
isolation and provide structure participart, I began to sing the of Communication, engagement,
I accompanied students' contributions with my voice, an and encouraged them to improvise and/or initiate new vocalizations/actions. While sharing music they were also developing finger isolation, aural skills and memory. Fo example: The improvisation I had with Rachel was... a bit of a 'wow' communicative tools I can (that work!) with music therapy
moment, really. My supervisor's comments that she wished but at the end of the day, music communicates so much on
she'd recorded it for me and that it was a strong example of she'd recorded it for me and that it was a strong example of own, and as a student music therapist especially it should musical communication really made me feel confident in my skills and, of course, proud of Rachel! We'd improvise to each other using short phrases until she played always be my priority - Reflective Journal to each other using short phrases, until she played began with Kumbaya, as Rachel had played the melody me last week. She played it again, using her index finger both hands (an octave apart) as I played an arpegiic A to whether learned this or if it was by ear, we did this again using Rachel already knew the melody or whether it was by ear, simple tunes 'You Are My Sunshine' and our Goodbye S but she began to play it with me! It was such an amazing moment. We didn't need to talk, we didn't need to sign, and making timing/pitch errors but always correcting the we didn't need to use any visuals. It was just the music, and Clinical Notes

I sang short, simple melodies that Ashle even articulate.

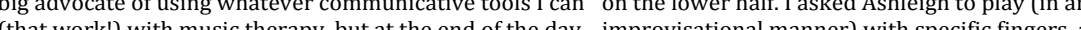

pen at a time on music communicates so much on its own, and as a student the top halfortly with me, and was able to isolatered Support improvisation, finger isolation, music therapist especially it should always be my priority. enthusiastically with me, and was able to isolate her
structure
and index finger and thumbs to play...Clinical Notes
- Jessica is able to remember the melody to Twinkle Twin Little Star and play this fluently as I play an accompanimer She's cen them as I show her she can do on her right hand. creative within, and we improvised a little song together. simple songs on piano, but am growing incredibly frustrat - Kumbaya - I sang/accompanied, Rachel played which astounded me. My visiting music therapist and I stuck notes, etc, but that I should not feel this way. She tol communication noteraction based purely on musical like just 'playing around' can in fact be very musically was a strong example of musical communication really ma We'd improvised on the keyboard, following proud of round and calling to each other using short phrases, until n accompaniment and sang to it. I'm unsure as to whethe Rachel l already knew the melody or whether it was by ea but she began to play it with me! It was such an amazing ment, and it made me so happy. We didn't need to talk, didn't need to sign, we didn't need to use any visuals. It wa 


\section{Appendix B - Case Vignette Information and Consent Form}

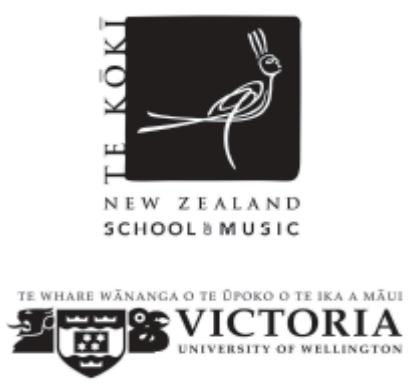

\section{MUSIC THERAPY PROGRAMME (MMUSTher)}

\section{Case Vignette - Information and Consent Form}

Hello. I am Sarah Curtain, the music therapy student at

As part of the requirements for my music therapy clinical placement I am required to complete an exegesis, illustrated by a vignette from my clinical work. I am writing to ask if I can describe the work I have done with in my exegesis.

The exegesis including the case vignette will be sent for examination. The examiners will be both internal and external to the New Zealand School of Music, Victoria University of Wellington. The exegesis will also be published in the Victoria University of Wellington library, in hard copy and as an online resource.

If you agree, the case vignette is likely to include background information about Anonymity will be protected whenever possible, with all information that might identify , and/or being removed. I will use a pseudonym when describing will not use photographs, audio, or video material in my case vignette.

Please take time to think about this, and ask any questions you might have. When you are sure you agree that I can write about in my case vignette, please sign both copies of this letter, keep one, and give one back to me. If you would like a copy of the case vignette and/or exegesis, it will be provided for you after the work has been completed and examined, following the conclusion of my placement.

I . be included in the case vignette described above.

Name: Signature: Date:

Parent/guardian or representative

Name: Signature: Date: Facility representative

This consent expires on (date) and may be withdrawn at any time by contacting the Music Therapy Programme Director at 6444635233 x35807 


\section{Appendix C - Case Study Information and Consent Form}
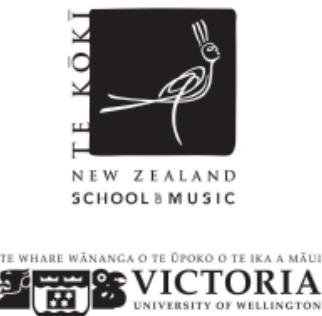

MUSIC THERAPY PROGRAMME (MMUsTher)

Case Study - Information and Consent Form

Hello. I am Sarah Curtain, the music therapy student at

As part of the requirements for my music therapy clinical placement I am required to complete an in-depth Case Study detailing my music therapy student practice with an individual or group of music therapy participants. I am writing to ask if I can describe the work I have done with in my case study.

The case study will be presented at an examination in January. The two examiners are likely to be both internal and external to the New Zealand School of Music, Victoria University of Wellington. The case study will also be shared with my lecturers at the New Zealand School of Music, and possibly also with other music therapy students and professionals at a music therapy seminar at the New Zealand School of Music.

If you agree, the case study is likely to include background information about . . I will not share it with anyone outside the groups named above, without your express permission. Anonymity will be protected whenever possible, with all information that might identify and/or being removed. At this stage I do not intend to use photographs, audio, or video material in my case study. If I decide this might enhance the work I will get back to you to ask for your explicit, separate, permission in writing,

Please take time to think about this, and ask any questions you might have. When you are sure you agree that I can write about in my case study, please sign both copies of this letter, keep one, and give one back to me. If you would like a copy of the case study, it will be provided for you after the work has been completed and examined, following the conclusion of my placement.

I give consent for information about to be included in the case study described above.

Name:...................................Signature:..................................Date

Parent/guardian or representative

Name:......................................Signature Date:

Facility representative

This consent expires on $01 / 06 / 17$ and may be withdrawn at any time by contacting the Music Therapy Programme Director at 6444635233 x35807 